Article (refereed)

Kay, A. L.; Davies, H. N.. 2008 Calculating potential evaporation from climate model data: a source of uncertainty for hydrological climate change impacts. Journal of Hydrology, 358 (3-4). 221-239. doi:10.1016/j.jhydrol.2008.06.005

Copyright (c) 2008 Elsevier B.V.

This version available at http://nora.nerc.ac.uk/3098/

NERC has developed NORA to enable users to access research outputs wholly or partially funded by NERC. Copyright and other rights for material on this site are retained by the authors and/or other rights owners. Users should read the terms and conditions of use of this material at http://nora.nerc.ac.uk/policies.html\#access

This document is the author's final manuscript version of the journal article, incorporating any revisions agreed during the peer review process. Some differences between this and the publisher's version remain. You are advised to consult the publisher's version if you wish to cite from this article.

www.elsevier.com 


\title{
Calculating potential evaporation from climate model data: a source of uncertainty for hydrological climate change impacts
}

Published: Journal of Hydrology (2008), 358, 221-239.

Kay, A.L. and Davies, H.N.

Centre for Ecology and Hydrology, Maclean Building, Crowmarsh Gifford, Wallingford, Oxfordshire, OX10 8BB, UK

Correspondence to: A.L. Kay

(Tel: +44 (0)1491 838800, Fax: +44 (0)1491 692424, Email: alkay@ceh.ac.uk)

\begin{abstract}
Evaporation is an important part of the water balance of a catchment, and estimates of potential evaporation (PE) are an important input to hydrological models. When modelling the hydrological impacts of climate change, using data from climate models, present models generally do not provide direct estimates of PE from the land surface. Estimates thus have to be calculated from other climate variables, and many existing formulae can be applied. This paper compares the well-established, more physicallybased but data-intensive, Penman-Monteith PE against a simple, temperature-based (Tbased) PE, when calculated from readily-available monthly climate model data over Britain (for five global and eight regional climate models). The performance of the two PE formulations is compared to MORECS PE (a gridded dataset derived by the UK Met Office from weather observations, using a modified Penman-Monteith formulation) for the baseline period 1961-1990, and the changes in the two PE estimates between the 1970s and the 2080s are compared. The results show that the T-based PE matches MORECS PE better than does Penman-Monteith PE, for all the climate models studied. However, the changes in the two types of PE between the 1970s and 2080s are different, for each of the climate models, and these affect the modelled hydrological impacts. This is illustrated using three example catchments spread across Britain. The uncertainty introduced by the PE formulation is less than that due to the climate model, but could still be important for some applications.
\end{abstract}

\section{Keywords}

Climate change impacts; hydrology; potential evaporation; uncertainty

\section{Introduction}

Evaporation from the land surface forms an important part of the water budget of a catchment, and needs to be accounted for within hydrological modelling. Continuous simulation hydrological models generally require (as a minimum) inputs of rainfall and potential evaporation (PE), where the latter is defined as 'the amount of water that would evaporate if sufficient water were available'. This contrasts with actual evaporation (AE), the rate of which is less than or equal to that of $\mathrm{PE}$ as it is dependant 
on the water available in the soil. Evaporation rates also depend on the type of land cover, but 'short grass' is often assumed as the standard.

There are numerous different formulae available in the literature for the calculation of PE. The complexity of these formulae varies greatly, from those dependant on just one atmospheric variable, often temperature (e.g. Thornthwaite 1948, Jensen and Haise 1963), to those requiring a number of other variables, such as relative humidity, wind speed and net solar radiation (e.g. Penman 1948, Priestley and Taylor 1972, Thom and Oliver 1977). When modelling under the current climate, observed data are potentially available to produce PE estimates using whichever formula a modeller prefers. For Britain, monthly PE data can be obtained from MORECS (Meteorological Office Rainfall and Evaporation Calculation System; Thompson et al. 1981, Hough and Jones 1997) for 201 squares on a $40 \times 40 \mathrm{~km}$ grid. These data are based on the PenmanMonteith equation for PE (Monteith, 1965), which involves all four of the atmospheric variables mentioned above. However, it is important to note that calibration of a hydrological model with such 'observed' data necessarily means that the calibration is tuned to the particular form of PE estimates chosen (e.g. Andreassian et al. 2004).

When modelling climate change impacts, data from (Global or Regional) Climate Models (GCMs or RCMs) are often used. Usually, climate models only provide direct estimates of $\mathrm{AE}$ from their land-surface schemes, not $\mathrm{PE}$, and not all of the variables required for the calculation of more complex $\mathrm{PE}$ formulae are available from all climate models. Sometimes replacement variables can be used instead (see Section 2), but not always. This leaves the modeller with somewhat of a dilemma: should they not use any climate model where calculation of their preferred form of PE is not possible, or should they change to an alternative, simpler, form of $\mathrm{PE}$, for which the required data are available for all of the climate models they wish to use? If the latter option were to be chosen, the same formula should ideally be used for all of the climate models, to maintain consistency of method.

Studies have shown that climate model uncertainty, particularly that of global models, is a major source of hydrological uncertainty under climate change (e.g. Arnell 1999; Jenkins and Lowe 2003; Wilby and Harris 2006; Cameron 2006; Prudhomme 2006; Graham et al. 2007; New et al. 2007; Kay et al., in press). This suggests that, in studies aiming to show as wide a range of impacts uncertainty as possible, the use of as many climate models as possible should be the preferred option. In addition, evidence from Oudin et al. (2005) suggests that the precise PE formulation is not critical for the performance of rainfall-runoff models. They compared the performance of four conceptual rainfall-runoff models when given (bias-corrected) PE data derived using 27 alternative formulae, for 308 catchments spread over three countries, and found that a large number of these formulae performed similarly, in terms of the fit of observed and simulated flows. Temperature-based formulae, in particular, were often found to perform similarly to (or better than) much more complex formulations. Similarly, Kannan et al. (2007) found that a simple temperature-based PE formula performed better than Penman-Monteith PE, for a distributed hydrological model run for a catchment in eastern England. Oudin et al. (2005) propose and test a simple, temperature-based PE formula, which initially seems like it could be a good choice for use with climate model data. 
However, in the context of climate change it may not be that simple. When considering changes in PE between current (or baseline) and future climates, it may be that changes in atmospheric variables other than temperature could have an important effect on overall changes in PE. This is demonstrated by the sensitivity study of Gong et al. (2006) for example, which shows that, for a large river basin in China, PenmanMonteith PE is generally more sensitive to changes in relative humidity than air temperature. This means that, for a climate change impact study, the use of more physically-based PE formulae, such as Penman-Monteith, could be preferable as they would include the effect of changes in more atmospheric variables. Arnell (1999) investigated the sensitivity of modelled changes in European runoff to PE formulation, under a given climate change scenario. He compared two PE formulae, PenmanMonteith and Priestley-Taylor (the latter includes only temperature and net radiation), and found that they predicted differing changes in runoff, even of different directions in a number of regions (including South-East England), despite giving similar estimates of current runoff.

This paper compares the performance of Penman-Monteith PE with the simple, temperature-based formula proposed by Oudin et al. (2005) (see Section 2), when calculated from climate model data (both from GCMs and RCMs). Monthly mean PE data calculated for the baseline period (1961-1990) for each method are compared to MORECS PE data over Britain for the same period (Section 3). The changes in the two forms of PE between the baseline period and the future period (1971-2100) are then compared (Section 4). Section 5 demonstrates the hydrological impact uncertainty (both for flooding and water resources applications), for a small number of catchments in Britain, caused by the use of the different PE formulae. The results are discussed in Section 6.

\section{Models and methods}

This section describes the two PE formulae that will be tested, introduces the (Global and Regional) climate models for which the formulae will be applied, and describes the hydrological model and the method used to demonstrate the effect of the different PE formulae on the hydrological impacts of climate change.

\subsection{PE formulae}

\subsubsection{Penman-Monteith PE}

The Penman-Monteith formulation for PE (Monteith, 1965) over short grass can be expressed as:

$$
P E_{P M}=\frac{1}{\lambda \rho_{w}} \frac{\Delta\left(R_{n}-G\right)+\rho_{a} c_{p}\left(e_{a}-e_{d}\right) / r_{a}}{\Delta+\gamma\left(1+r_{s} / r_{a}\right)},
$$

where

$\lambda$ is the latent heat flux (taken as $2.45 \times 10^{6} \mathrm{~J} / \mathrm{kg}$ ), 
$\rho_{w}$ is the density of water (taken as $1000 \mathrm{~kg} / \mathrm{m}^{3}$ ),

$\rho_{a}$ is the density of air (taken as $1.00 \mathrm{~kg} / \mathrm{m}^{3}$ ),

$c_{p}$ is the specific heat of air (taken as $1013 \mathrm{~J} / \mathrm{kg} /{ }^{\circ} \mathrm{C}$ )

$\gamma$ is the psychrometric constant (taken as $0.066 \mathrm{kPa} /{ }^{\circ} \mathrm{C}$ ),

$R_{n}$ is the net solar radiation $\left(\mathrm{J} / \mathrm{m}^{2} / \mathrm{s}\right)$,

$G$ is the soil heat flux (taken as $0 \mathrm{~J} / \mathrm{m}^{2} / \mathrm{s}$ ),

$e_{a}=e\left(T_{a}\right)=0.611 \exp \left(17.27 T_{a} /\left(T_{a}+237.3\right)\right)$ is the saturation vapour pressure $(\mathrm{kPa})$, where $T_{a}$ is the air temperature $\left({ }^{\circ} \mathrm{C}\right)$,

$\Delta=\mathrm{d} e_{a} / \mathrm{d} T_{a}=17.27 \times 237.3 e_{a} /\left(T_{a}+237.3\right)^{2}$ is the slope of the vapour pressure curve $\left(\mathrm{kPa} /{ }^{\circ} \mathrm{C}\right)$,

$e_{d}=e\left(T_{d}\right)$ is the actual vapour pressure $(\mathrm{kPa})$, with $T_{d}$ the dew-point temperature $\left({ }^{\mathrm{o}} \mathrm{C}\right)$,

$r_{a}=208 / W_{2}$ is the aerodynamic resistance $(\mathrm{s} / \mathrm{m})$, where $W_{2}$ is the wind speed $(\mathrm{m} / \mathrm{s})$ at a height of $2 \mathrm{~m}$, and

$r_{s}$ is the surface resistance (taken as $70 \mathrm{~s} / \mathrm{m}$ for short grass),

giving $P E_{P M}$ in units of $\mathrm{m} / \mathrm{s}$ (see Allen et al. (1994) for more details). Although developed for application with weather data at a daily time-step, mean monthly weather data can be used to compute mean monthly $P E_{P M}$, which will be very similar to the average of daily $P E_{P M}$ computed from daily weather data (Allen et al. 1998, p69).

The way in which MORECS implements a slightly modified Penman-Monteith formulation, to convert synoptic station data into estimates of PE on a $40 \times 40 \mathrm{~km}$ grid over Britain, is described in detail by Thompson et al. (1981) and Hough et al. (1996), with an overview given by Hough and Jones (1997). Briefly, daily sunshine, temperature, vapour pressure and wind speed data taken from synoptic stations are normalised/standardised, before being interpolated to grid-square average values. These are then reverse normalised/standardised before being used in a Penman-Monteith PE formulation similar to that given above, to calculate daily $\mathrm{PE}$ and subsequently weekly/monthly mean PE.

The main difference between the formulation described above and that used within MORECS is a correction for the assumption that surface temperature equals the measured (air) temperature. MORECS also allows a seasonal grass cover so uses a different value of $r_{s}$ for each month, with values in the range $44.5 \mathrm{~s} / \mathrm{m}$ (late spring) to $88.7 \mathrm{~s} / \mathrm{m}$ (winter) (with an average of about $73 \mathrm{~s} / \mathrm{m}$ ). Also, MORECS does not assume $\mathrm{G}=0$, but the effect of this term is small, for a grass land cover over 10-30 day periods (Allen et al. 1994). One feature of the MORECS implementation necessary for the calculation of Penman-Monteith PE from climate model data is the use of wind speed at a height of $10 \mathrm{~m}$ rather than at $2 \mathrm{~m}$. Assuming a logarithmic profile, this gives $r_{a}=243 / W_{10}$, where $W_{10}$ is the wind speed $(\mathrm{m} / \mathrm{s}$ ) at a height of $10 \mathrm{~m}$ (see Thompson et al. (1981), section 4.2.2.2).

\subsubsection{Temperature-based PE}

The simple, temperature-based (T-based) PE formulation suggested by Oudin et al (2005), based on a study of the performance of over 25 existing PE formulations when used as input to four different hydrological models for over 300 catchments, is given by: 


$$
\begin{array}{ll}
P E_{T}=\frac{R_{e}}{\lambda \rho_{w}} \frac{T_{a}+5}{100} & \text { if } T_{a}+5>0, \\
P E_{T}=0 & \text { otherwise, }
\end{array}
$$

where $\lambda$ and $\rho_{w}$ are as in section 2.1.1, $R_{e}$ is extraterrestrial radiation $\left(\mathrm{J} / \mathrm{m}^{2} / \mathrm{s}\right)$, which is dependant on latitude and Julian day only (see Allen et al. 1994), and $T_{a}$ is the mean daily air temperature $\left({ }^{\circ} \mathrm{C}\right)$, giving $P E_{T}$ in units of $\mathrm{m} / \mathrm{s}$. Although this formulation was developed for use with (long-term) mean daily data, there is evidence that monthly data can be used in models similar to this to compute monthly $P E_{T}$, without significantly affecting results (Federer et al. 1996). Note that this T-based PE formulation does not allow negative values for PE, however the Penman-Monteith formulation can result in negative values. Here, all negative PE values have been reset to zero.

\subsubsection{Comparison of MORECS PE with T-based PE derived from MORECS' T}

As an initial test of the T-based formulation of PE, the monthly time-series of gridinterpolated mean temperature data were taken from within MORECS and applied in the T-based formulation, to calculate monthly mean T-based PE on the MORECS 40 x $40 \mathrm{~km}$ grid. Figure 1 compares the resulting T-based PE with MORECS PE, as mean monthly values and mean annual totals (for 1961-1990) averaged over two regions, over the north and south of Britain. This shows that, compared to (PenmanMonteith) MORECS PE, the T-based formulation generally underestimates in the winter and spring but overestimates in the summer, with a slightly later peak. The mean annual PE totals are very similar, but with T-based PE slightly less than MORECS PE.

\subsection{Climate models}

Global Climate Models (GCMs) are currently run, of necessity, on quite coarse grids (generally $\sim 300 \mathrm{~km}$ over the UK). Regional Climate Models (RCMs) are limited-area versions of global models and so can be run on finer grids (generally $\sim 50 \mathrm{~km}$ over the UK), with improved representation of topography etc. When forced by GCM boundary conditions, RCMs can provide dynamic downscaling of GCM climate change scenarios. However, RCMs have not currently been run for all available GCMs. Consequently, data from a set of GCMs is applied here, as well as data from a set of RCMs. 


\subsubsection{Global Climate Models}

There are a number of GCMs, developed by various institutes across the globe, and these produce different effects on global climate from given emissions scenarios. They have different climate sensitivities (the change in global mean temperature under a doubling of $\mathrm{CO}_{2}$ ) and show different patterns of change in temperature and precipitation (see Figures 24-27 of Hulme et al. (2002)). Various monthly mean climate variables, under the SRES A2 emissions scenario (IPCC 2000), were obtained from the IPCC data distribution centre (ipcc-ddc.cru.uea.ac.uk) for five of the GCMs used for the IPCC Third Assessment Report (TAR): HadCM3, CCSR/NIES, CGCM2, CSIRO-Mk2 and ECHAM4 (Table 1). These have been used to calculate both the Penman-Monteith and T-based PE in this study.

Table 1

For the GCMs, Penman-Monteith PE is calculated as described in Section 2.1.1, including the values for $r_{s}$ and $G$ as suggested by Allen et al. (1994), rather than as used by MORECS. As summarised in Table 1 , solar radiation, $R_{n}$, mean air temperature, $T_{a}$, and the $10 \mathrm{~m}$ wind speed, $W_{10}$, were available for each GCM, but different data had to be used for the calculation of actual vapour pressure, $e_{d}$, in each case. ECHAM4 is the only GCM to give dew-point temperature, which is the recommended variable, however these data were only available for 1990 onwards so the baseline monthly mean dewpoint temperature was calculated for 1990-1994. Specific humidity was used in the calculation of $e_{d}$ for the CGCM2 and CCSR GCMs, whilst relative humidity was used for the HadCM3 GCM. For the CSIRO GCM, minimum temperature had to be used in place of dew-point temperature, as no humidity data were available. Data from two further GCMs - NCAR and GFDL (USA) - are available from the IPCC, but the NCAR data only run from 1980, so none of the baseline means can be established, and the GFDL data do not include the information on humidity or dew-point temperature required to calculate Penman-Monteith PE.

\subsubsection{Regional Climate Models}

The EU-funded PRUDENCE project (Christensen et al. 2007; http://prudence.dmi.dk) produced high-resolution climate change scenarios for Europe (for 2071-2100) based on the use of different RCMs nested within a Hadley Centre GCM (HadAM3H, except for the Hadley RCM which is nested in HadAM3P). Control runs (for 1961-1990) are also available. Some of these data (at a monthly time-step) are used to calculate both the Penman-Monteith and T-based monthly mean PE in this study. The data for each RCM are available on its native grid (different for each RCM), but also interpolated onto a common grid (of a similar resolution); that of the Climate Research Unit (the definition of the CRU grid, and details of the interpolation method, are available from http://prudence.dmi.dk). The interpolations onto the CRU grid have been used here, for ease of comparison, and the SRES A2 emissions scenario has been used for all of the RCMs. The eight RCMs represented here are from the Met Office Hadley Centre (MOHC), DMI, ETH, GKSS, KNMI, MPI, SMHI and UCM (see Table 1). Deque et al. (2007) provide a brief description of each of these RCMs, with references for further detail. The RCM of ICTP (Italy) could not be used due to lack of available wind speed data. Where more than one run of the RCM is available (i.e. with different initial conditions), only the first run has been used here. 
For the RCMs, Penman-Monteith PE is calculated as described in Section 2.1.1, including the values used for $r_{s}$ and $G$ by MORECS. As summarised in Table 1, mean air temperature, $T_{a}$, and the $10 \mathrm{~m}$ wind speed, $W_{10}$, are available for each of the RCMs (except that the scalar wind speed for the ETH RCM has to be calculated from the two directional wind speeds, as $W_{10}{ }^{2}=U_{10}{ }^{2}+V_{10}{ }^{2}$ ) and the net solar radiation, $R_{n}$, can be calculated as the sum of the net short wave and net long wave radiation. However, three of the RCMs (MOHC, UCM and KNMI) do not provide dew-point temperature, $T_{d}$, so specific humidity had to be used in the calculation of actual vapour pressure, $e_{d}$.

\subsection{Impact modelling}

In order to investigate the effect that uncertainty in PE changes has on the modelled hydrological impacts of climate change, a continuous rainfall-runoff model was used to simulate the effect on projected changes in high and low flows for three example catchments in Britain. The catchment numbers (from the UK National River Flow Archive: www.ceh.ac.uk/data/nrfa/) are 30004 (the Lymn at Partney Mill, in East Anglia), 42012 (the Anton at Fullerton, in southern England) and 96001 (the Halladale at Halladale, in northern Scotland). The catchments represent a range of catchment types, with varying rainfall regimes. Details of the catchments are given in Table 2 and their locations are shown on the map in Figure 2.

\subsubsection{Rainfall-runoff model}

The rainfall-runoff model applied is the Probability Distributed Model (PDM) of Moore Figure 2 Table 2 (1985, 2007). This is a relatively simple but flexible conceptual model (with a probability-distributed soil moisture store feeding into fast and slow routing stores), which takes input time-series of catchment-averaged rainfall and PE and outputs timeseries of flow at the catchment outlet. The model has been widely applied in Britain and it forms part of the River Flow Forecasting System (Institute of Hydrology 1992). A relatively parameter-sparse version of the model is applied here, with five catchmentspecific parameters, four of which require calibration (the fifth is set using soils data; see Kay et al. (2007) for more detail).

Two of the three example catchments (30004 and 96001) have hourly catchmentaverage rainfall data and corresponding hourly flow data (for January 1985 to December 2001), so are calibrated and run with an hourly model time-step. The third catchment (42012) is calibrated and run with a daily model time-step, using daily catchmentaverage rainfall and flow data (for January 1975 to December 1999). All three catchments are calibrated with monthly catchment-average PE time-series data (equally divided over the number of model time-steps in each month), where the monthly catchment-average series are obtained from MORECS through simple areal-weighting of the series from all $40 \times 40 \mathrm{~km}$ MORECS boxes covering the catchment. 


\subsubsection{Delta-change downscaling}

In order to limit problems caused by any bias in climate model rainfall or PE (and to allow for the fact that the rainfall-runoff model is essentially calibrated for use with MORECS Penman-Monteith PE), the monthly changes in rainfall and PE suggested by the climate models are applied, respectively, to baseline observed rainfall and MORECS PE time-series. This approach is often termed the delta-change method of downscaling, and has been applied in a number of previous climate change impact studies (e.g. Reynard et al. 2001, Schreider et al. 2000, New et al. 2007). In its simplest form, the delta-change method involves the application of monthly mean (percentage or absolute) changes to each value in the baseline daily (or sub-daily) time-series. It is this form of the method which is applied here, although more complex variations are possible (e.g. Prudhomme et al. 2002, Reynard et al. 2004). The great advantage of this method is the ease with which alternative changes, suggested by different climate models, emissions scenarios etc., can be applied. A disadvantage is that it is limited by the ordering and variability of events in the baseline series, as these remain essentially unchanged in the future series. However, it serves here to demonstrate the potential uncertainty introduced by the PE calculation method.

\section{Performance for baseline PE}

This section attempts to compare the (Penman-Monteith and T-based) PE estimates derived from climate model data with MORECS PE data, as this is essentially what the rainfall-runoff model is calibrated for use with. The comparison is done in terms of monthly means (mm/day) for regions covering North and South Britain, to look at the reproduction of the annual cycle in two different regions, and (for the RCMs) in terms of maps of mean annual totals, to look at the reproduction of spatial patterns. All averaging is done for the period 1961-1990.

Comparison of MORECS PE with PE derived from GCM data is not easy, due to the very different resolution of the GCM grids ( $\sim 300 \mathrm{~km}$ over the UK) compared to that of MORECS (40 x $40 \mathrm{~km}$ ). Comparison of MORECS PE with PE derived from RCMs is easier due to the similar resolutions of the data sets. As data for each of the eight PRUDENCE RCMs are available on a common (CRU) grid (see Section 2.2.2), the MORECS PE data have also been interpolated onto that grid (using straightforward areal-weighting, and allocating missing values to those CRU boxes where less than $80 \%$ of the area is covered by MORECS $40 \times 40 \mathrm{~km}$ boxes). Boxes covering regions over North and South Britain have then been selected (Figure 3), and the MORECS monthly mean PE calculated for each of these regions is used as the basis for the comparison with both GCM- and RCM-derived monthly mean PE.

\subsection{Global Climate Models}

For each GCM, the grid box whose centre is within, or closest to, each region (North and South Britain) has been chosen for comparison with the MORECS regional monthly mean PE. Figure 3 shows the location of the grid box centres across the UK region, for each of the five GCMs used here, and highlights those grid boxes used for the comparison with MORECS PE (for the North and South regions shown by the 
shaded areas on Figure 3). Comparisons are made between mean monthly PE (calculated as $\mathrm{mm} /$ day) as well as mean annual PE (m), where the latter is calculated from the former using the true number of days in each month. This allows for the fact that some GCMs work with 360-day years (12 months, each with 30 days).

The results (Figure 4) show that GCM Penman-Monteith PE is generally lower than MORECS PE for most, if not all, of the year, in both the North and South of Britain. The exception is the CSIRO GCM, where Penman-Monteith PE is significantly higher than MORECS PE for the whole year, over both regions. This means that the PenmanMonteith mean annual PE is higher than MORECS PE for the CSIRO GCM but lower than MORECS PE for the other four GCMs. In contrast, the T-based mean annual PE totals are closer to those of MORECS PE, as these are generally higher than MORECS $\mathrm{PE}$ in the summer but lower for the rest of the year. The T-based PE also tends to peak slightly later in the year than does MORECS PE. This monthly pattern of under/overestimation from T-based PE in comparison to MORECS PE seems to be due to the Tbased formulation, as the same was seen for T-based PE calculated from MORECS' temperature data (Section 2.1.3).

The main factor affecting the performance of GCM-derived PE (compared to MORECS PE) is likely to be bias in the GCMs' reproduction of current climate. In particular, a major factor in the significant over-estimation of Penman-Monteith PE for the CSIRO GCM appears to be bias in minimum temperature $\left(T_{\min }\right)$, which had to be used in place of dew-point temperature $\left(T_{\mathrm{d}}\right)$ (see Section 2.2.1). In general the use of $T_{\min }$ (from early morning) instead of $T_{\mathrm{d}}$ (as an average over the day) could cause problems over Britain, as the former would generally be lower than the latter in a relatively humid climate, thus the actual vapour pressure $e_{d}$ calculated from $T_{\min }$ is too low, hence $P E_{P M}$ is too high compared to MORECS PE (which uses the mean of four vapour pressures measured through the day). However, in the case of the CSIRO GCM there seems to be a specific negative bias in $T_{\min }$ in autumn, winter and spring, in comparison with $T_{\min }$ from other GCMs. This, together with an apparent positive bias in summer temperature, is probably the cause of the over-estimation of Penman-Monteith PE throughout the year.

\subsection{Regional Climate Models}

For each RCM, regional monthly means (mm/day) are calculated over the same boxes covering North and South Britain as used for calculating the MORECS regional monthly mean PE, thus providing a more direct comparison than is possible for the GCMs. Also, mean annual PE (m) is calculated from mean monthly PE for each region, using the true number of days in each month, to allow for the fact that all of these RCMs work with 360-day years and thus providing a fairer comparison against MORECS PE data.

The results (Figure 5) show that, as for the GCMs, RCM Penman-Monteith PE is generally lower than MORECS PE for most, if not all, of the year, for all eight RCMS, hence mean annual Penman-Monteith PE is lower than MORECS PE too. RCM Tbased PE is, again, higher than MORECS PE in the summer (with a slightly later peak), but lower for the rest of the year (probably due to the T-based formulation, see Section 2.1.3), so annual totals are closer to (but still always lower than) those of MORECS PE. 
This general underestimation of Penman-Monteith PE from RCM data is consistent with results from Ekstrom et al. (2007), who derive their Penman-Monteith PE in a similar way but using data from the HadRM3H RCM and show significant underestimation over NW England, especially in summer, compared to PE derived from observational data.

Figure 6 shows maps of the gridded mean annual PE for each RCM and each PE type, compared to interpolated MORECS PE (and to interpolated T-based PE derived from MORECS' temperature data). The results suggest that RCM T-based PE actually provides a better representation of the general North-West to South-East gradient of annual PE across Britain than does RCM Penman-Monteith PE. However, it needs to be borne in mind that this is largely due to overestimation of PE in summer and underestimation of PE for the rest of the year. For some of the RCMs (e.g. MOHC and DMI), the Penman-Monteith PE shows the greater spatial variability that is evident in the MORECS PE, on top of the underlying gradient. That is, these maps are quite 'patchy', whereas such variability is not seen in the T-based PE (the maps of which have very distinct bands across the country). Thus the variability is presumably due to the other climate variables involved in the calculation of Penman-Monteith PE.

It should be noted that the land-sea mask of the climate model can be important for PE, and much of the variation seen on the edges of the mapped areas for RCM PE is due to some grid boxes being classified as sea rather than land in some RCMs. Such boxes are over-marked with smaller white squares on the maps in Figure 6, where the interpolated land-sea mask has been derived separately for each model, from its native land-sea mask, by the PRUDENCE team. The effect of this is particularly evident in the Penman-Monteith PE.

\section{Comparison of changes in PE}

This section looks at the potential changes in PE under climate change (from the 1970s to the 2080s), in particular the differences in these changes when calculated using Penman-Monteith PE or T-based PE, for different GCMs and RCMs.

\subsection{Global Climate Models}

Graphs of the percentage change in each type of PE over North and South Britain, for each of the five GCMs, are shown in Figure 7. These show that the change in T-based $\mathrm{PE}$ is positive throughout the year, for each GCM, generally with larger percentage increases in winter than in summer. In contrast, the changes in Penman-Monteith PE are sometimes negative for some GCMs, particularly for Northern Britain, usually with a greater range of changes (minimum to maximum) across the year and with more monthto-month variability in the changes than is seen for T-based PE. This difference in changes in T-based and Penman-Monteith PE is not unexpected, given that climate models suggest consistent increases in temperature over Northern Europe, and so increases in T-based PE, but complex interactions between multiple variables lead to less clear-cut patterns of change in Penman-Monteith PE. 
All of the GCMs show annual increases in each type of PE, but the changes in PenmanMonteith PE are generally lower than those for T-based PE in the North (except for the ECHAM4 GCM), whereas the opposite is often true of the changes in the South. The CSIRO GCM shows the smallest increase (for both PE types and both regions). However, there is more variation in the ordering of the rest of the GCMs for the two PE types. For instance, the ECHAM4 GCM shows the largest increase in Penman-Monteith PE (for both regions) whilst the CCSR GCM shows the largest increase in T-based PE (for both regions). The ordering of the GCMs with the T-based PE changes is completely consistent between the two regions.

Note that the calculation of percentage change in PE is sometimes difficult, mainly for winter months, as the baseline PE can be (at or) near zero, potentially resulting in percentage increases that are very large. This affects the results for HadCM3 and ECHAM4, where the plotted percentage increases have been capped at $100 \%$. Also, the zero percentage changes shown for the winter months for CGCM2 are due to zero PE being calculated for both the current and future periods.

\subsection{Regional Climate Models}

Graphs of the percentage change in each type of PE over North and South Britain, for each of the eight RCMs, are shown in Figure 8. As for the GCMs, the change in Tbased PE is positive throughout the year, whilst the changes in Penman-Monteith PE are sometimes negative, and are generally much more variable across the year, with a greater range of changes, than the T-based changes. All of the RCMs show annual increases in PE, with the MOHC and UCM RCMs showing consistently larger increases than the rest of the RCMs, for both regions and both PE types. There is much more variation in the ordering of the rest of the RCMs between PE types and regions.

Figure 9 shows maps of the gridded percentage change in mean annual PE, for each RCM and each PE type. Most of the maps show a general gradient of changes, with larger increases in the south-east than in the north-west. The gradient is more pronounced in the Penman-Monteith PE than in the T-based PE, with some grid boxes in the north-west even show decreases in mean annual Penman-Monteith PE for some RCMs. It is also clear from the maps that the MOHC and UCM RCMs are much more extreme in terms of changes in Penman-Monteith PE than the other RCMs.

\section{Impact uncertainty}

This section looks at the additional uncertainty in the hydrological impacts of climate change due to the use of different forms of PE in the hydrological modelling. As described in Section 2.3.2, the monthly percentage changes for the two PE types are applied to the baseline time-series of MORECS PE, as the model is calibrated using the latter and because this method avoids problems with bias in the climate model data (see below). Similarly, the monthly percentage changes in rainfall are applied to the baseline rainfall time-series so that, for a given climate model, the same changed rainfall series is applied with each of the two changed PE time-series. The differing impacts between each pair of results for a given climate model are therefore due to the differing PE input. 
The use of the delta change method in the hydrological impact modelling means that any bias in a climate model's reproduction of PE (and rainfall) does not matter directly, as it does not affect the water balance within the hydrological model. However, it does matter indirectly, as the ability of a climate model to represent the current climate affects the confidence that can be given to its results under climate change. Thus the results of Section 3 should be borne in mind here.

The impact is considered for the whole flow range - low, medium and high - for three catchments in Britain (see details in Section 2.3). Note that the impacts are generally more consistent between the eight RCMs than they are between the five GCMs, as each of the RCMs is nested within (essentially) the same global atmospheric model (see Section 2.2.2).

\subsection{Impact on low to average flows}

Figure 10 shows the modelled annual and seasonal percentage changes in Q95 (the flow exceeded $95 \%$ of the time) for the three example catchments, using the changes in rainfall and (each type of) PE suggested by each of the five GCMs and eight RCMs. The results suggest that the PE type used to define the changes in PE can make a difference to the modelled impact on low flows, which may be quite significant in some cases. For instance, for the Scottish catchment (96001) the impact modelled using one PE type can be of the opposite sign to that using the alternative PE type for some climate models (e.g. HadCM3, ECHAM4, DMI, KNMI) especially in winter (DJF) and for GCMs. The same is true for the catchment in southern England (42012), although here it is most noticeable in spring (MAM) and for RCMs. There can also be large differences in impact even where the two PE types result in the same sign of change. For instance, for catchment 42012 using the ECHAM4 GCM, the modelled reduction in Q95 in each season using T-based PE is approximately one-half to two-thirds of that using Penman-Monteith PE. Neither is there any obvious consistency between climate models, in terms of the impact modelled with the different PE types. For instance, for the Anglian catchment (30004) using the UCM RCM, the impact on winter Q95 using the T-based PE is about two-thirds of that using Penman-Monteith PE (approximately $+40 \%$ vs $+60 \%$ ), whereas for the same catchment using the CCSR GCM the impact on winter Q95 using the Penman-Monteith PE is about two-thirds of that using T-based PE (approximately $+34 \%$ vs $+50 \%$ ).

Figure 11 shows the modelled annual and seasonal percentage changes in the median flow (Q50) for the three example catchments, using the changes in rainfall and PE suggested by each of the climate models. The results are similar to those for Q95, in that there are cases where the modelled impacts have quite different values, sometimes even of a different sign, depending on which PE type is used, and there is no obvious consistency in the differences by PE type for different climate models.

\subsection{Impact on high flows}

Figure 12 shows the modelled annual and seasonal percentage changes in Q5 (the flow exceeded $5 \%$ of the time) for the three example catchments, using the changes in Figure 12 rainfall and PE suggested by each of the climate models. The results in this case are 
again similar to those for Q95 and Q50, although there are fewer cases where the different types of PE result in opposite-signed changes in Q5. However, the differences could still be important, particularly, it seems, for the catchment in southern England (42012). Here, for almost all of the RCMs, the use of T-based PE results in larger increases (in some cases by $100 \%$ or more) in annual (and winter and spring) Q5 than does the use of Penman-Monteith PE. This is also relatively consistent with the results for the HadCM3 GCM, which is the coupled version of the global model that the PRUDENCE RCMs are nested within. Also for this catchment, using the ECHAM4 GCM with Penman-Monteith PE suggests a reduction in winter Q5 of about 30\% whereas using T-based PE suggests an increase of about $7 \%$.

Figure 13 shows the modelled percentage changes in flood peaks at five return periods $(2,5,10,20$ and 50 years) for the three example catchments, using the changes in rainfall and PE suggested by each of the climate models. In general, these results follow the patterns seen for changes in winter Q5 (Figure 12), which is unsurprising as winter is the main flood season in the UK (Bayliss and Jones 1993). Thus here, again, the effect of using T-based as against Penman-Monteith PE seems to be particularly evident for the catchment in southern England, with the use of T-based PE resulting in larger changes at each return period than does Penman-Monteith PE, for most of the RCMs, and with the ECHAM4 GCM giving increases in flood peaks at most return periods when using T-based PE, but decreases at most return periods when using PenmanMonteith PE. Note that the results for the 50-year return period require some extrapolation of the fitted flood frequency curve, and so involve much more uncertainty than the results for the lower return periods.

\section{Discussion and Conclusions}

This paper has applied two very different formulations to derive PE for a set of climate models; one method which is data-intensive (needing temperature, humidity, radiation and wind speed data) but more physically-based (Penman-Monteith) and one which is simpler but more empirical, needing only temperature data (T-based). Surprisingly, a comparison with MORECS PE (a gridded dataset derived by the UK Met Office from weather observations, using a modified Penman-Monteith formulation) over Britain showed that using the T-based method with climate model data for the period 19611990 generally gave a better fit than applying the Penman-Monteith formulation. The two methods also give very different changes in PE when applied to climate model data for the period 2071-2100 (under the A2 emissions scenario), and this can, potentially, have a large effect on the subsequent modelled hydrological impacts of climate change.

It is perhaps not surprising that this affect is most noticeable for modelled low, or even median, flows, but it is perhaps surprising how large an effect this can have even for a fast-responding catchment in Scotland. As far as high flows are concerned, it would be expected for catchments in the south and east of England to be most affected by the differing changes in PE, as such catchments lose a higher proportion of their rainfall through evaporation (and receive less rainfall) than catchments to the north or west of Britain. They also tend to have deeper soils, so can build up larger soil moisture deficits. In particular, catchments with a high baseflow index, such as 42012, are worse affected, due to their even greater water storage capacity and thus longer hydrological 'memory'. 
In general, the results suggest that the hydrological impact uncertainty due to PE formulation is less than that due to GCM structure, or even RCM structure. Thus the main aim for the impact modeller should probably still be to apply as many climate models as possible. However, some combinations of PE type and climate model do still lead to individual impacts outside the range of results given by the alternative PE type with the whole set of climate models applied here. For instance, for catchment 30004, the impact on winter Q95 with Penman-Monteith PE and the UCM RCM is larger than that with T-based PE for any climate model applied. Neither is it possible to say with any certainty what effect the use of an alternative form of PE will be, given the impacts resulting from the use of one type of $\mathrm{PE}$, as there is no obvious pattern that can be applied. Thus the possibility of a quite different set of impacts, if an alternative form of $\mathrm{PE}$ is applied, must be borne in mind.

The problem is further complicated by the fact that T-based PE performed better than Penman-Monteith in a comparison for the current climate, even though PenmanMonteith PE is more physically-based. This is probably due to reliability issues with some of the other variables required for the calculation of Penman-Monteith PE, when these are produced by climate models; such problems are clearly lessened when only temperature data are required. Ekstrom et al. (2007) discuss suspected problems with the PE derived from HadRM3H climate model data using the Penman-Monteith formulation, for their modelling over NW England and the Rhine basin, and describe site-specific methodologies applied to avoid these. Of course, many more PE formulations exist than the two applied for this paper, and other methods, perhaps intermediate in complexity to these two, should probably be tested on climate model data, but the T-based formulation applied here is one of the simplest and seems to perform well, at least for annual totals over Britain (although the tendency towards overestimation in summer and underestimation for the rest of the year could be a problem from some applications).

The impact modeller thus has to make a pragmatic choice, preferably including as many climate models as possible and estimating PE for each climate model in a consistent way. Consideration of the particular impact being modelled and of the circumstances under which it may be especially affected by differences in PE, perhaps including a sensitivity study, may help the modeller to decide on the best course of action.

\section{Acknowledgements}

GCM data were obtained from the IPCC data distribution centre (http://ipccddc.cru.uea.ac.uk). RCM data were obtained through the PRUDENCE data archive (http://prudence.dmi.dk), funded by the EU through contract EVK2-CT2001-00132. The authors particularly thank Dr O.B. Christensen for help with the PRUDENCE data.

\section{References}

Allen, R.G., Pereira, L.S., Raes, D. and Smith, M. (1998). Crop evapotranspiration (guidelines for computing crop water requirements). FAO Irrigation and Drainage Paper No. 56. 
Allen, R.G., Smith, M., Pereira, L.S. and Perrier, A. (1994). An update for the calculation of reference evapotranspiration. ICID Bulletin, 43(2), 35-92.

Andreassian, V., Perrin, C. and Michel, C. (2004). Impact of imperfect potential evapotranspiration knowledge on the efficiency and parameters of watershed models. Journal of Hydrology, 286, 19-35.

Arnell, N.W. (1999). The effect of climate change on hydrological regimes in Europe: a continental perspective. Global Environmental Change, 9, 5-23.

Bayliss, A.C., Jones, R.C. (1993). Peaks-over-threshold flood database: Summary statistics and seasonality. IH Report No. 121, Institute of Hydrology, Wallingford.

Cameron, D. (2006). An application of the UKCIP02 climate change scenarios to flood estimation by continuous simulation for a gauged catchment in the northeast of Scotland, UK (with uncertainty). Journal of Hydrology, 328, 212-226.

Christensen, J.H., Carter, T.R., Rummukainen, M. and Amanatidis, G. (2007) Evaluating the performance and utility of regional climate models: the PRUDENCE project. Climatic Change, 81, 1-6.

Déqué, M., Rowell, D. P., Lüthi, D., Giorgi, F., Christensen, J. H., Rockel, B., Jacob, D., Kjellström, E., de Castro, M. and van den Hurk, B. (2007) An intercomparison of regional climate simulations for Europe: assessing uncertainties in model projections. Climatic Change, 81, 53-70.

Ekstrom, M., Jones, P.D., Fowler, H.J., Lenderink, G., Buishand, T.A. and Conway, D. (2007). Regional climate model data used within the SWURVE project 1: projected changes in seasonal patterns and estimation of PET. Hydrology and Earth System Sciences, 11(3), 1069-1083.

Federer, C.A., Vorosmarty, C. and Fekete, B. (1996). Intercomparison of methods for calculating potential evaporation in regional and global water balance models. Water Resources Research, 32(7), 2315-2321.

Gong, L., Xu, C.-y., Chen, D., Halldin, S. and Chen, Y.D. (2006). Sensitivity of the Penman-Monteith reference evapotranspiration to key climatic variables in the Changjiang (Yangtze River) basin. Journal of Hydrology, 329, 620-629.

Graham, L.P., Hageman, S., Jaun, S. and Beniston, M. (2007). On interpreting hydrological change from regional climate models. Climatic Change, 81, 97-122.

Hough, M. and Jones, R.J.A. (1997). The United Kingdom Meteorological Office rainfall and evaporation calculation system: MORECS version 2.0 - an overview. Hydrology and Earth System Sciences, 1(2), 227-239. 
Hough, M., Palmer, S., Weir, A., Lee, M., and Barrie, I. (1996). The Meteorological Office Rainfall and Evaporation Calculation System: MORECS version 2.0 (1995). An update to Hydrological Memorandum 45, The Met. Office, Bracknell.

Hulme, M., Jenkins, G.J., Lu, X.,Turnpenny, J.R., Mitchell, T.D., Jones, R.G., Lowe, J., Murphy, J.M., Hassell, D., Boorman, P., McDonald, R. and Hill, S. (2002). Climate Change Scenarios for the United Kingdom: The UKCIP02 Scientific Report. Tyndall Centre for Climate Change Research, School of Environmental Sciences, University of East Anglia, Norwich, UK.

Institute of Hydrology (1992). River Flow Forecasting System: Model developers' course notes. Report to National Rivers Authority, IH Wallingford.

IPCC (2000). Special report on emissions scenarios (SRES): A special report of Working Group III of the Intergovernmental Panel on Climate Change. Cambridge University Press, Cambridge.

Jenkins, G. and Lowe, J. (2003). Handling uncertainties in the UKCIP02 scenarios of climate change. Hadley Centre technical note 44.

Jensen, M.E. and Haise, H.R. (1963). Estimating evapotranspiration from solar radiation. Journal of Irrigation and Drainage Division, ASCE 89 (LR4), 15-41.

Kannan, N., White, S.M., Worrall, F. and Whelan, M.J. (2007). Sensitivity analysis and identification of the best evapotranspiration and runoff options for hydrological modelling in SWAT-2000. Journal of Hydrology, 332, 456- 466.

Kay, A.L., Davies, H.N., Bell, V.A. and Jones, R.G. (2008). Comparison of uncertainty sources for climate change impacts: flood frequency in England. Climatic Change, in press.

Kay, A.L., Jones, D.A., Crooks, S.M., Kjeldsen, T.R. and Fung, C.F. (2007). An investigation of site-similarity approaches to generalisation of a rainfall-runoff model. Hydrology and Earth System Sciences, 11, 500-515.

Monteith, J.L., (1965). Evaporation and environment. Symposia of the Society for Experimental Biology, 19, 205-234.

Moore, R.J. (1985). The probability-distributed principle and runoff production at point and basin scales. Hydrolog. Sci. J., 30, 273-297.

Moore, R.J. (2007). The PDM rainfall-runoff model. Hydrology and Earth System Sciences, 11, 483-499.

New, M., Lopez, A., Dessai, S. and Wilby, R. (2007). Challenges in using probabilistic climate change information for impact assessments: an example from the water sector. Philosophical Transactions of the Royal Society A, 365, 2117-2131. 
Oudin, L., Hervieu, F., Michel, C., Perrin, C., Andreassian, V., Anctil, F. and Loumagne, C. (2005). Which potential evapotranspiration input for a lumped rainfallrunoff model? Part 2 - Towards a simple and efficient potential evapotranspiration model for rainfall-runoff modelling. Journal of Hydrology, 303, 290-306.

Penman, H.L. (1948). Natural evaporation from open water, bare soil and grass. Proceedings of the Royal Society of London 193, 120-145.

Priestley, C.H.B. and Taylor, R.J. (1972). On the assessment of surface heat fluxes and evaporation using large-scale parameters. Monthly Weather Review 100, 81-92.

Prudhomme C. (2006). GCM and downscaling uncertainty in modelling of current river flow: why is it important for future impacts? In: Climate variability and change Hydrological impacts, Proceedings of the Fifth FRIEND World Conference, Havana, Cuba, November 2006, IAHS Publ. 308.

Prudhomme, C., Reynard, N. and Crooks, S. (2002). Downscaling of global climate models for flood frequency analysis: where are we now? Hydrological Processes, 16, 1137-1150.

Reynard, N.S., Crooks, S.M. and Kay, A.L. (2004). Impact of climate change on flood flows in river catchments. Report to Department for Environment, Food and Rural Affairs and the Environment Agency, Project SC010011 Technical Report, CEH Wallingford, March 2004, 97pp.

Reynard, N.S., Prudhomme, C. and Crooks, S.M. (2001). The flood characteristics of large U.K. rivers: Potential effects of changing climate and land use. Climatic Change, 48, 343-359.

Schreider, S.Y., Smith, D.I. and Jakeman, A.J. 2000. Climate change impacts on urban flooding. Climatic Change, 47, 91-115.

Thom, A.S. and Oliver, H.R. (1977). On Penman's equation for estimating regional evaporation. Quarterly Journal of the Royal Meteorological Society 103, 345-357.

Thompson, N., Barrie, I.A. and Ayles, M. (1981). The Meteorological Office Rainfall and Evaporation Calculation System: MORECS (July 1981). Hydrological Memorandum No. 45, Met Office, Bracknell.

Thornthwaite C.W. (1948). An approach towards a rational classification of climate. Geographical Review 38, 55-94.

Wilby R.L. and Harris, I. (2006). A framework for assessing uncertainties in climate change impacts: Low-flow scenarios for the River Thames, UK. Water Resources Research, 42, W02419, doi:10.1029/2005WR004065. 
Table 1 Summary of the GCMs and RCMs, and their respective variables used for the calculation of Penman-Monteith PE

\begin{tabular}{cll}
\hline Name & Host country & Variables used for Penman-Monteith PE \\
\hline IPCC TAR GCM & & \\
HadCM3 & UK & DSWF, TMP, WIND, RHUM \\
CCSR/NIES & Japan & DSWF, TMP, WIND, SPFH \\
CGCM2 & Canada & DSWF, TMP, WIND, SPFH \\
$\begin{array}{l}\text { CSIRO-Mk2 } \\
\text { ECHAM4 }\end{array}$ & Australia & DSWF, TMP, WIND, TMIN \\
$\begin{array}{l}\text { PRUDENCE RCM } \\
\text { (driving GCM) }\end{array}$ & & DSWF, TMP, WIND, DEW2 \\
$\begin{array}{l}\text { MOHC } \\
\text { (HadAM3P) }\end{array}$ & UK & SWnet, LWnet, t2m, w10m, q2m \\
$\begin{array}{l}\text { DMI } \\
\text { (HadAM3H) }\end{array}$ & Denmark & SWnet, LWnet, t2m, w10m, td2m \\
$\begin{array}{l}\text { ETH } \\
\text { (HadAM3H) }\end{array}$ & Switzerland & SWnet, LWnet, t2m, u10m, v10m, td2m \\
$\begin{array}{l}\text { GKSS } \\
\text { (HadAM3H) }\end{array}$ & Germany & SWnet, LWnet, t2m, w10m, td2m \\
$\begin{array}{l}\text { KNMI } \\
\text { (HadAM3H) }\end{array}$ & Netherlands & SWnet, LWnet, t2m, w10m, q2m \\
$\begin{array}{l}\text { MPI } \\
\text { (HadAM3H) }\end{array}$ & Germany & SWnet, LWnet, t2m, w10m, td2m \\
$\begin{array}{l}\text { SMHI } \\
\text { (HadAM3H) }\end{array}$ & Sweden & SWnet, LWnet, t2m, w10m, td2m \\
$\begin{array}{l}\text { UCM } \\
\text { (HadAM3H) }\end{array}$ & Spain & SWnet, LWnet, t2m, w10m, q2m \\
\hline
\end{tabular}

Key: DSWF, total incident solar radiation; SWnet, net SW radiation (positive); LWnet, net LW radiation (positive); TMP/t2m, mean air temperature; WIND/w10m, wind speed; $\mathrm{u} 10 \mathrm{~m} / \mathrm{v} 10 \mathrm{~m}$, wind velocity; DEW2/td2m, dew-point temperature; SPFH/q2m, specific humidity; RHUM, relative humidity; TMIN, mean minimum air temperature.

Table 2 Details of the example catchments.

\begin{tabular}{crrrrrrr}
\hline $\begin{array}{c}\text { Catchment } \\
\text { number }\end{array}$ & $\begin{array}{c}\text { Catchment } \\
\text { area }\left(\mathrm{km}^{2}\right)\end{array}$ & $\begin{array}{l}\text { Altitude } \\
\text { range }(\mathrm{m})\end{array}$ & $\begin{array}{c}\text { Mean } \\
\text { altitude } \\
(\mathrm{m})\end{array}$ & $\begin{array}{c}\text { Baseflow } \\
\text { index }\end{array}$ & $\begin{array}{c}\text { Mean } \\
\text { flow } \\
\left(\mathrm{m}^{3} \mathrm{~s}^{-1}\right)\end{array}$ & $\begin{array}{c}\text { SAAR }_{61-90} \\
(\mathrm{~mm})\end{array}$ & $\mathrm{R}$ \\
\hline 30004 & 61.6 & $15-142$ & 65 & 0.66 & 0.50 & 685 & 0.37 \\
42012 & 185.0 & $41-253$ & 113 & 0.96 & 1.83 & 773 & 0.40 \\
96001 & 204.6 & $23-580$ & 175 & 0.25 & 5.03 & 1096 & 0.68 \\
\hline
\end{tabular}

SAAR $_{61-90}=$ standard annual average rainfall for $1961-1990, \mathrm{R}=$ mean annual runoff $/$ mean annual rainfall. 


\section{List of Figures}

Figure 1 Comparison of MORECS PE with T-based PE derived from MORECS' temperature data, for regions over the north and south of Britain (highlighted on the right-hand map). The top plot compares mean monthly MORECS PE (squares/solid lines) and T-based PE (triangles/dotted lines), for the north and south regions (respectively filled and open symbols). The bottom plot compares mean annual MORECS PE (hatched bars) and T-based PE (open bars).

Figure 2 Map showing the locations of the example catchments.

Figure 3 Map showing the location of the GCM grid box centres across the UK region, for each of the five GCMs, highlighting those used for comparison with MORECS. The shaded areas show the interpolated MORECS grid squares used for North and South Britain.

Figure 4 Plots comparing Penman-Monteith and T-based monthly mean PE ( $\mathrm{mm} /$ day) derived from the five GCMs (respectively filled triangles/dashed line and open triangles/dotted line) with MORECS PE (filled squares/solid line), over regions covering North and South Britain. The final plot in each group of six for the two regions compares Penman-Monteith and T-based mean annual PE (m) (respectively hatched and open bars) for each GCM with MORECS mean annual PE (solid line).

Figure 5 Plots comparing Penman-Monteith and T-based monthly mean PE ( $\mathrm{mm} /$ day) derived from the eight PRUDENCE RCMs (respectively filled triangles/dashed line and open triangles/dotted line) with MORECS PE (filled squares/solid line), over regions covering North and South Britain. The final plot in each group of nine for the two regions compares Penman-Monteith and T-based mean annual PE (m) (respectively hatched and open bars) for each GCM with MORECS mean annual PE (solid line).

Figure 6 Maps comparing MORECS mean annual PE (top left, interpolated onto the CRU grid) with Penman-Monteith and T-based mean annual PE derived from the eight PRUDENCE RCMs. Boxes over-marked with smaller white squares indicate those boxes designated as sea (rather than land) for each different RCM. Also shown for comparison is the T-based mean annual PE derived from MORECS temperature data (top right, interpolated onto the CRU grid).

Figure 7 Plots comparing the potential changes in Penman-Monteith and T-based monthly mean PE derived from GCMs (respectively filled triangles/dashed line and open triangles/dotted line), over regions covering North and South Britain. The final plot in each group of six for the two regions compares percentage changes in Penman-Monteith and T-based mean annual PE (respectively hatched and open bars) for each GCM.

Figure 8 Plots comparing the potential changes in Penman-Monteith and T-based monthly mean PE derived from RCMs (respectively filled triangles/dashed line and open triangles/dotted line), over regions covering North and South Britain. The final plot in each group of nine for the two regions compares percentage changes in Penman-Monteith and T-based mean annual PE (respectively hatched and open bars) for each RCM.

Figure 9 Maps comparing the potential changes in Penman-Monteith and T-based mean annual PE derived from RCMs. 
Figure 10 Bar charts showing modelled annual and seasonal percentage changes in Q95 for three example catchments, for each GCM (left-hand column, left-to-right bar order: HadCM3; ECHAM4; CSIRO; CCSR; CGCM2) and RCM (right-hand column, left-to-right bar order: MOHC; DMI; ETH; GKSS; KNMI; MPI; SMHI; UCM). The solid bars indicate the results when the changes in Penman-Monteith $\mathrm{PE}$ are applied, whilst the outlined bars indicate the results when the changes in Tbased PE are applied instead.

Figure 11 As Figure 10, but showing the modelled annual and seasonal percentage changes in the median flow (Q50).

Figure 12 As Figure 10, but showing the modelled annual and seasonal percentage changes in Q5.

Figure 13 As Figure 10, but showing the modelled percentage changes in flood peaks at five different return periods $(2,5,10,20$ and 50 years).
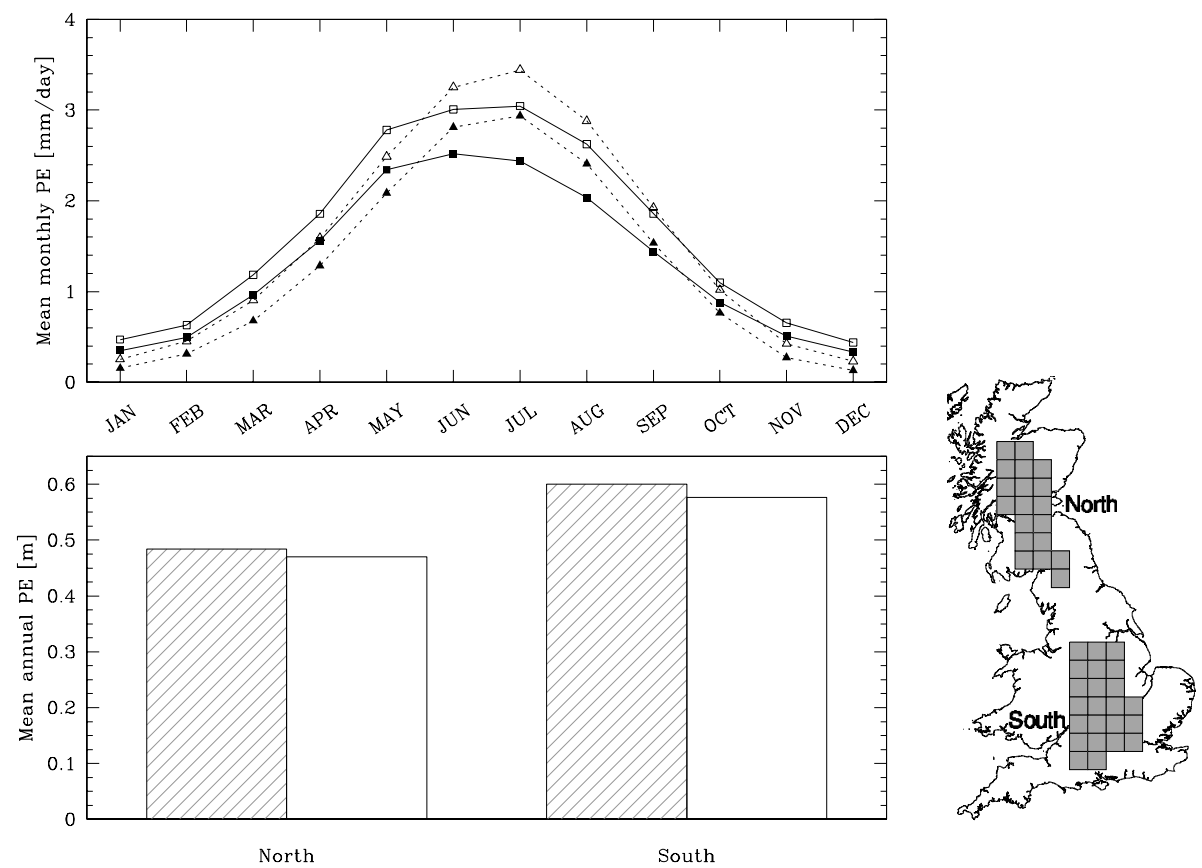

Figure 1 Comparison of MORECS PE with T-based PE derived from MORECS' temperature data, for regions over the north and south of Britain (highlighted on the right-hand map). The top plot compares mean monthly MORECS PE (squares/solid lines) and T-based PE (triangles/dotted lines), for the north and south regions (respectively filled and open symbols). The bottom plot compares mean annual MORECS PE (hatched bars) and T-based PE (open bars). 


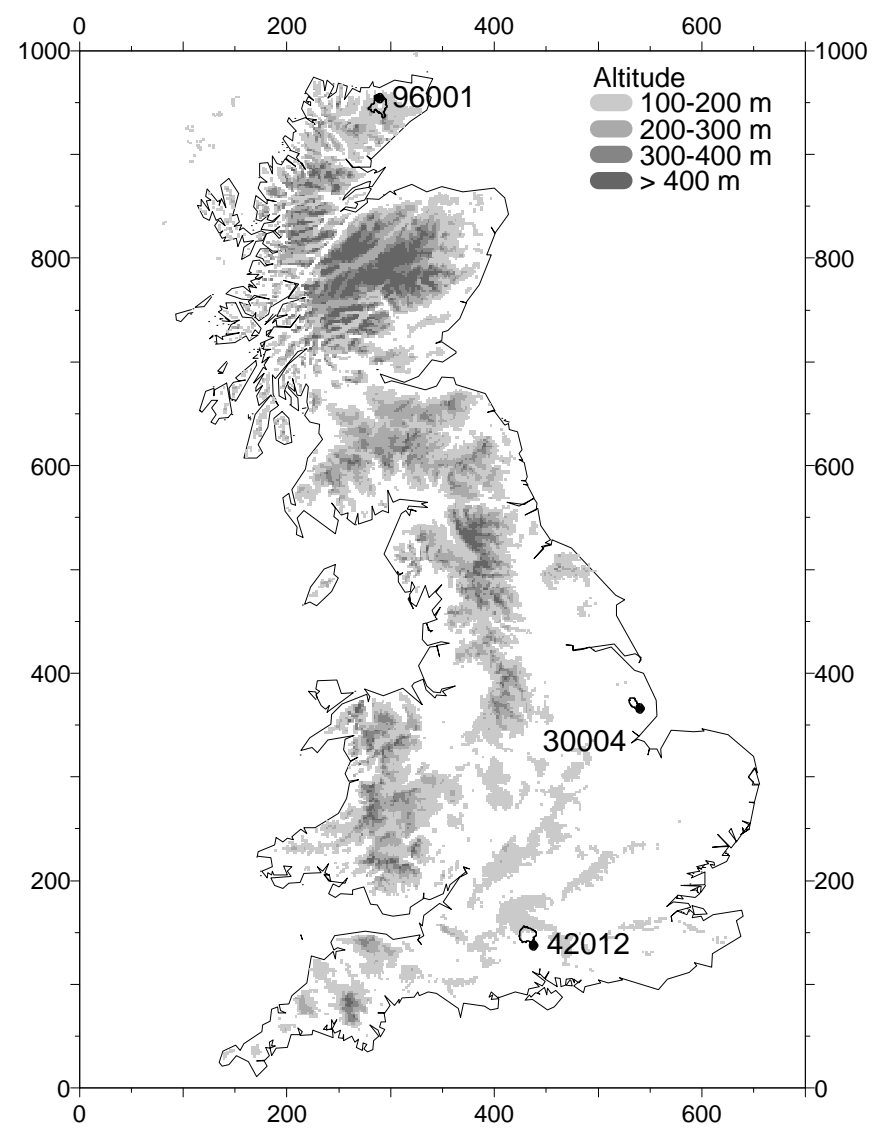

Figure 2 Map showing the locations of the example catchments.

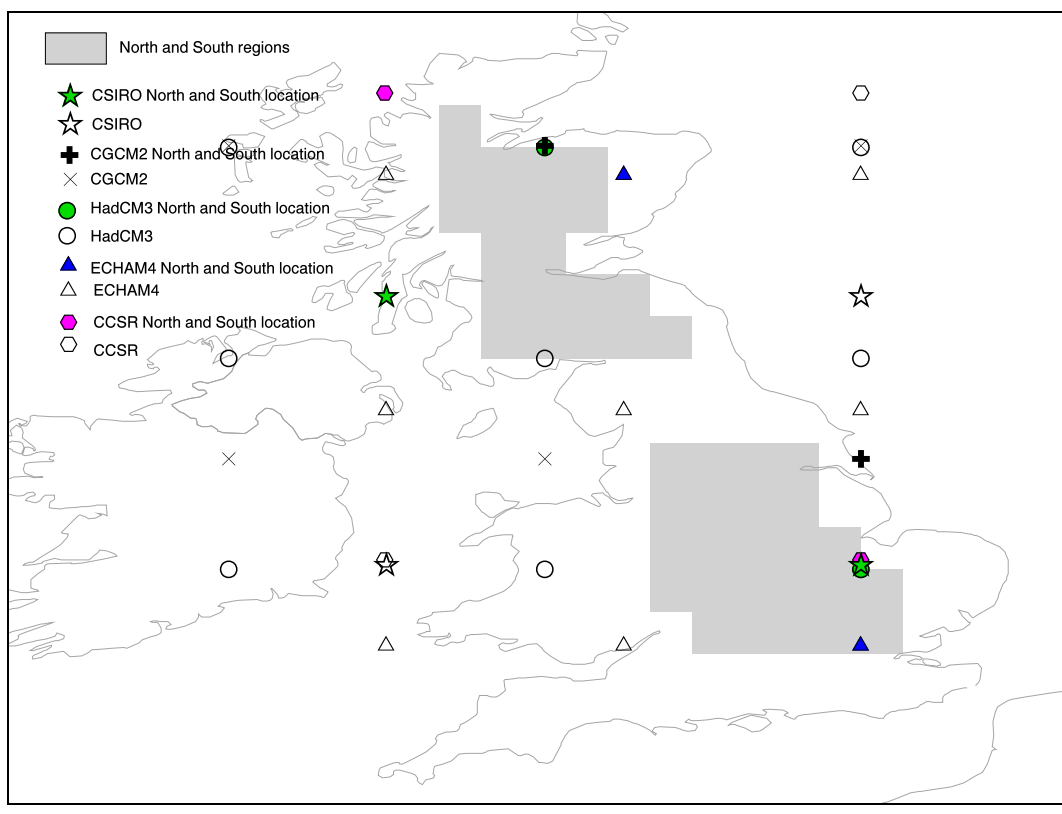

Figure 3 Map showing the location of the GCM grid box centres across the UK region, for each of the five GCMs, highlighting those used for comparison with MORECS. The shaded areas show the interpolated MORECS grid squares used for North and South Britain. 

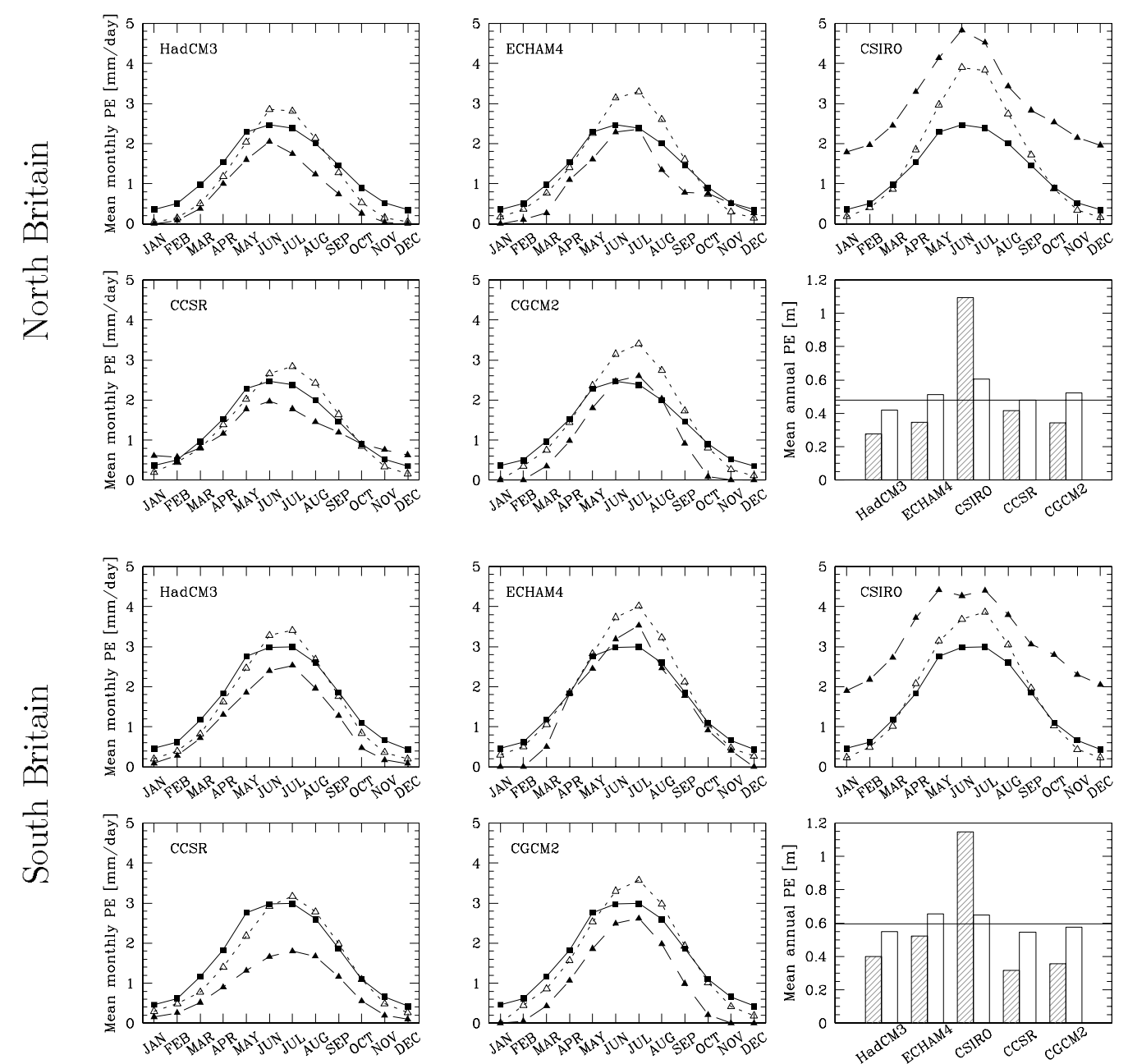

Figure 4 Plots comparing Penman-Monteith and T-based monthly mean PE $(\mathrm{mm} /$ day) derived from the five GCMs (respectively filled triangles/dashed line and open triangles/dotted line) with MORECS PE (filled squares/solid line), over regions covering North and South Britain. The final plot in each group of six for the two regions compares PenmanMonteith and T-based mean annual PE (m) (respectively hatched and open bars) for each GCM with MORECS mean annual PE (solid line). 

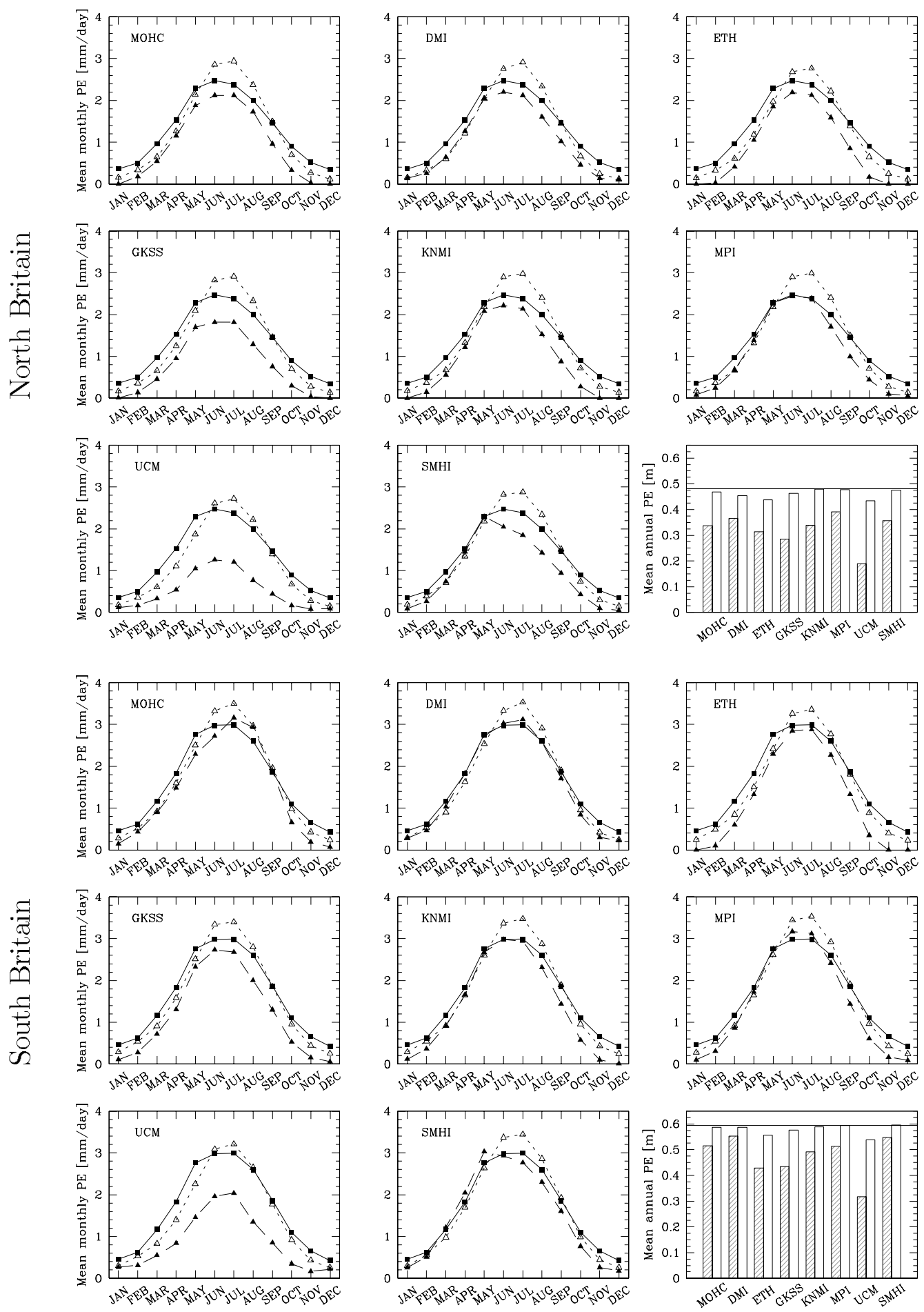

Figure 5 Plots comparing Penman-Monteith and T-based monthly mean PE (mm/day) derived from the eight PRUDENCE RCMs (respectively filled triangles/dashed line and open triangles/dotted line) with MORECS PE (filled squares/solid line), over regions covering North and South Britain. The final plot in each group of nine for the two regions compares Penman-Monteith and T-based mean annual PE (m) (respectively hatched and open bars) for each GCM with MORECS mean annual PE (solid line). 
MORECS Penman-Monteith

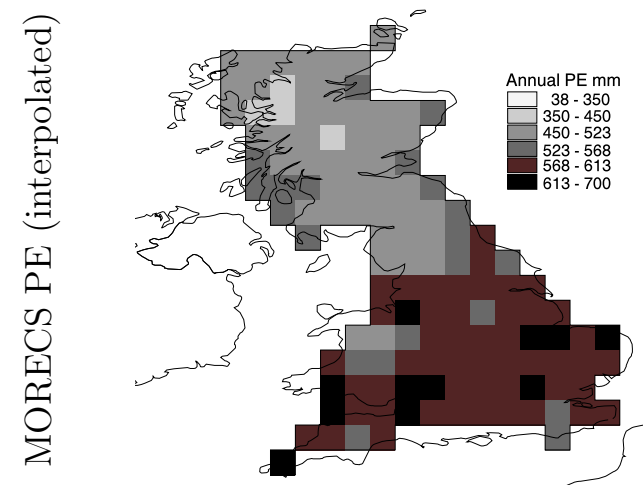

Penman-Monteith
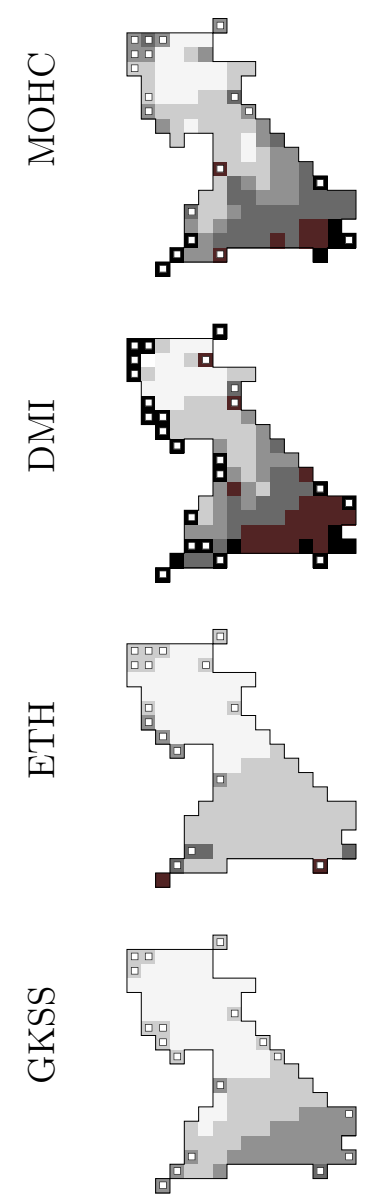

T-based
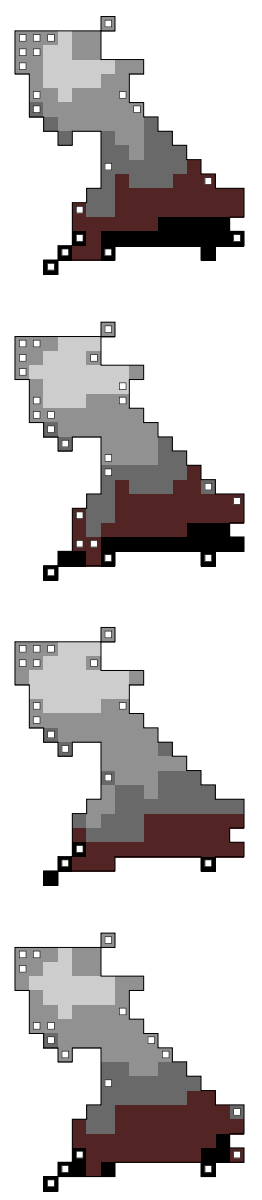

T-based from MORECS T

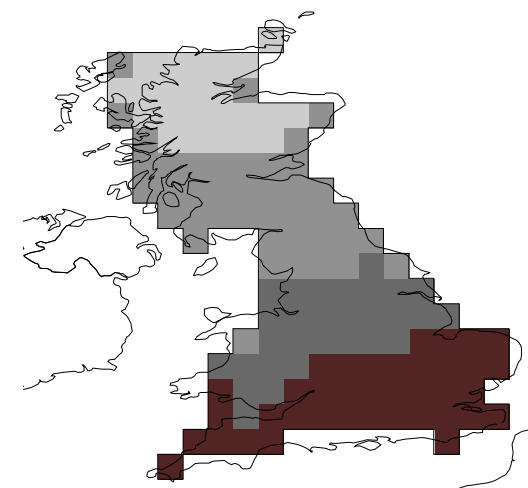

Penman-Monteith

T-based
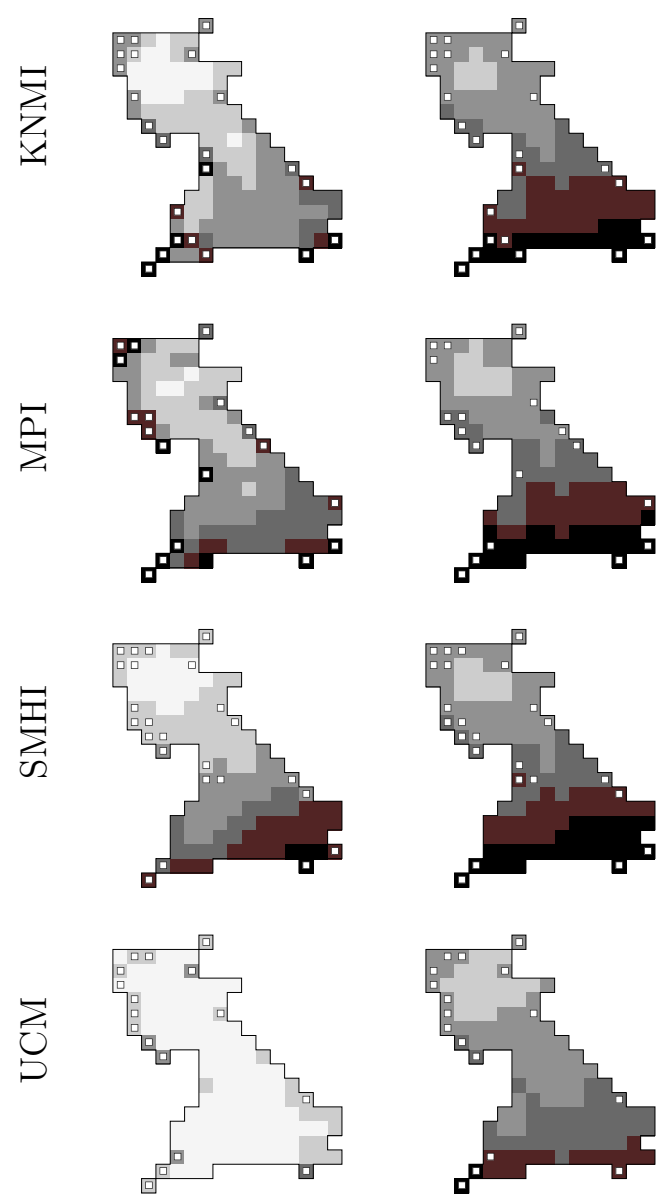

Figure 6 Maps comparing MORECS mean annual PE (top left, interpolated onto the CRU grid) with Penman-Monteith and T-based mean annual PE derived from the eight PRUDENCE RCMs. Boxes over-marked with smaller white squares indicate those boxes designated as sea (rather than land) for each different RCM. Also shown for comparison is the T-based mean annual PE derived from MORECS temperature data (top right, interpolated onto the CRU grid). 

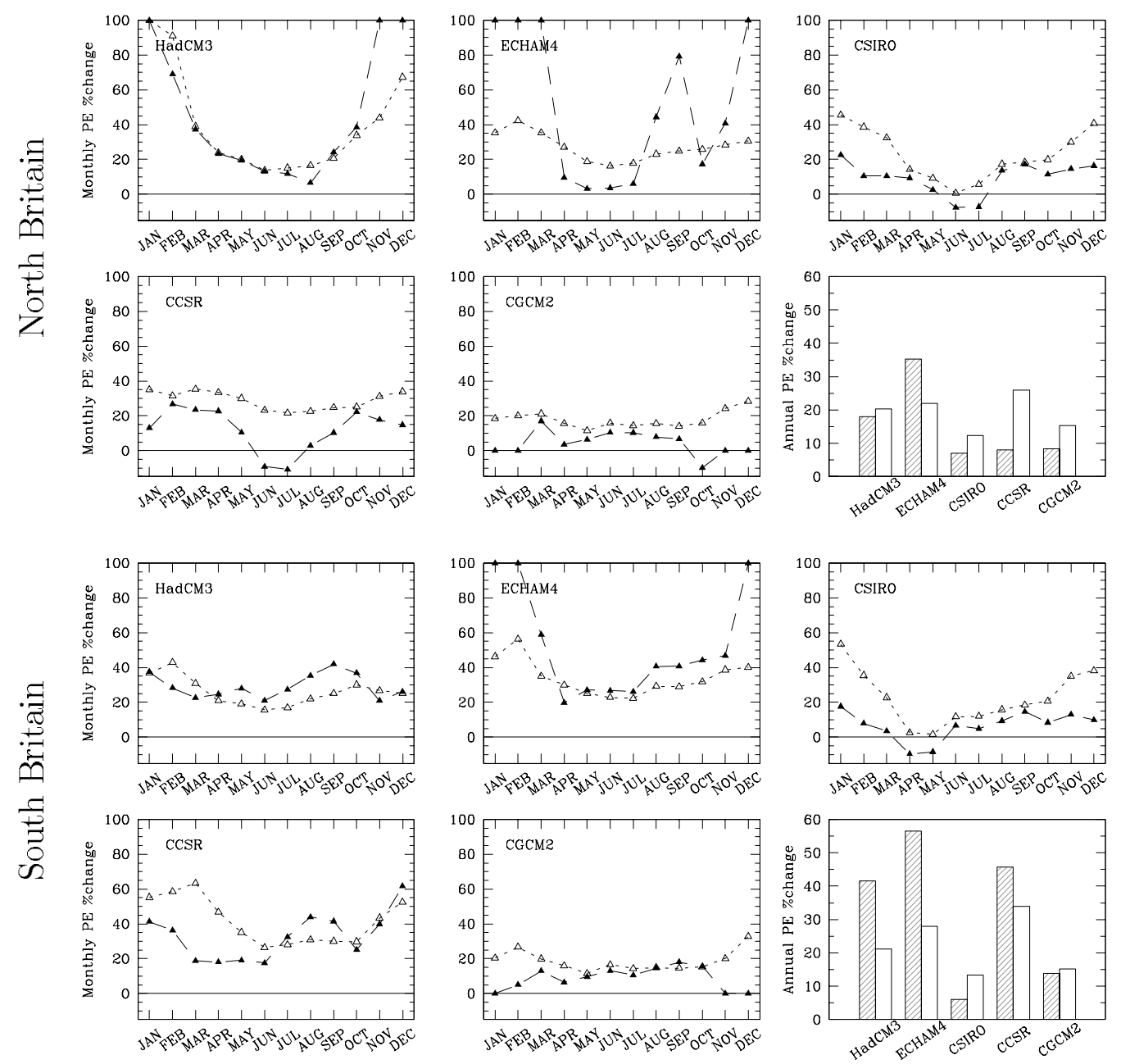

Figure 7 Plots comparing the potential changes in Penman-Monteith and T-based monthly mean PE derived from GCMs (respectively filled triangles/dashed line and open triangles/dotted line), over regions covering North and South Britain. The final plot in each group of six for the two regions compares percentage changes in Penman-Monteith and T-based mean annual PE (respectively hatched and open bars) for each GCM. 

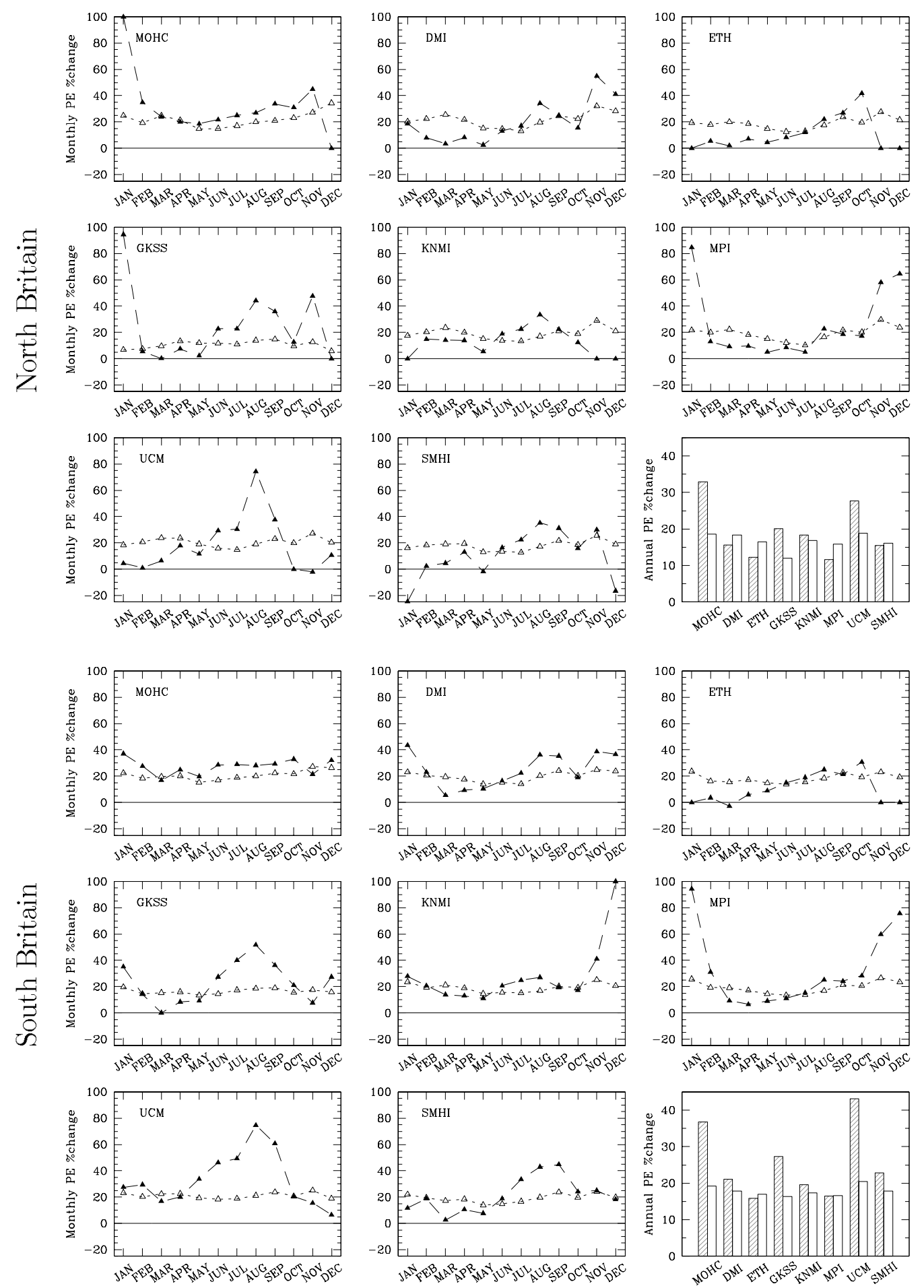

Figure 8 Plots comparing the potential changes in Penman-Monteith and T-based monthly mean PE derived from RCMs (respectively filled triangles/dashed line and open triangles/dotted line), over regions covering North and South Britain. The final plot in each group of nine for the two regions compares percentage changes in Penman-Monteith and T-based mean annual PE (respectively hatched and open bars) for each RCM. 

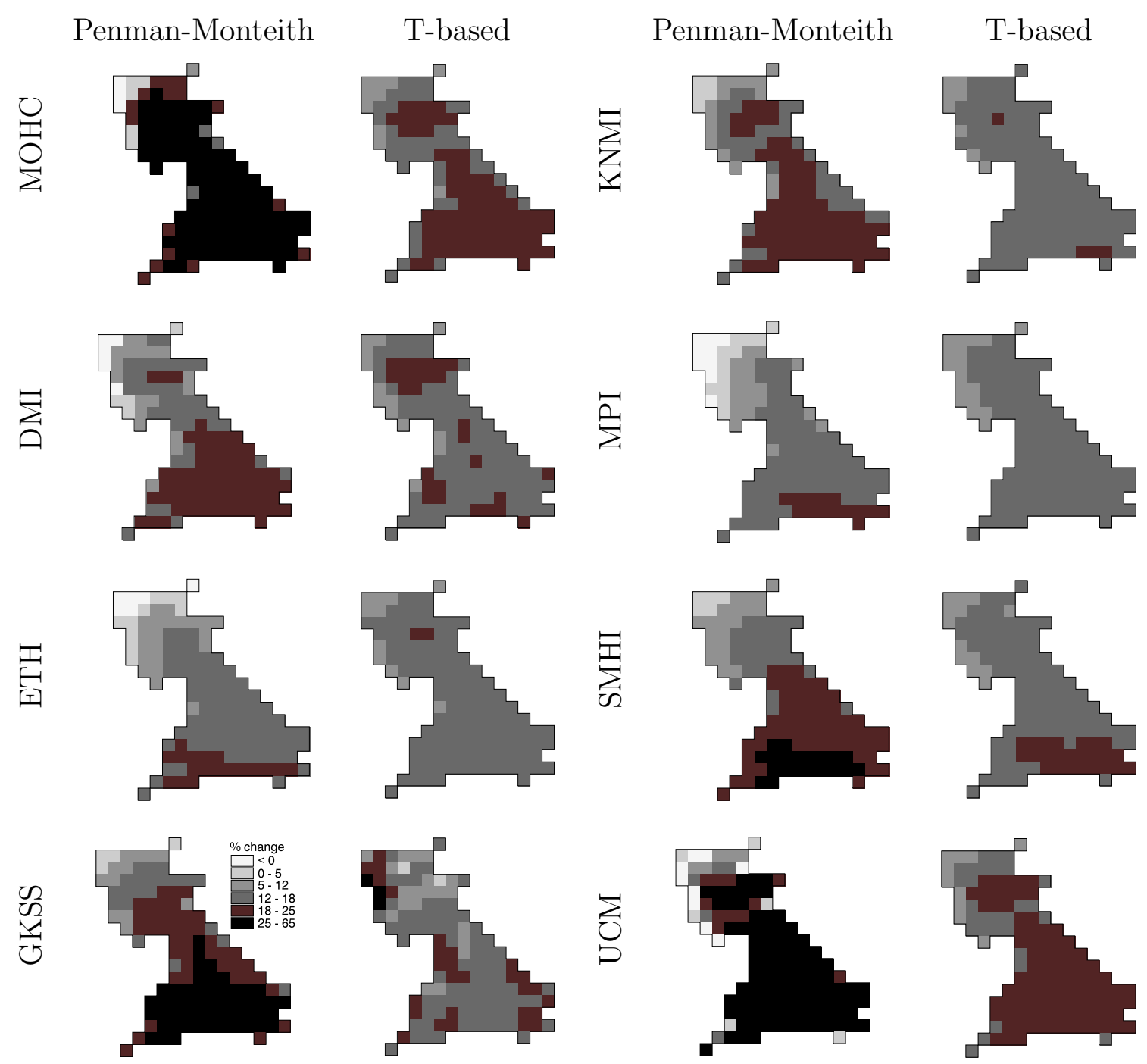

Figure 9 Maps comparing the potential changes in Penman-Monteith and T-based mean annual PE derived from RCMs. 
GCMs
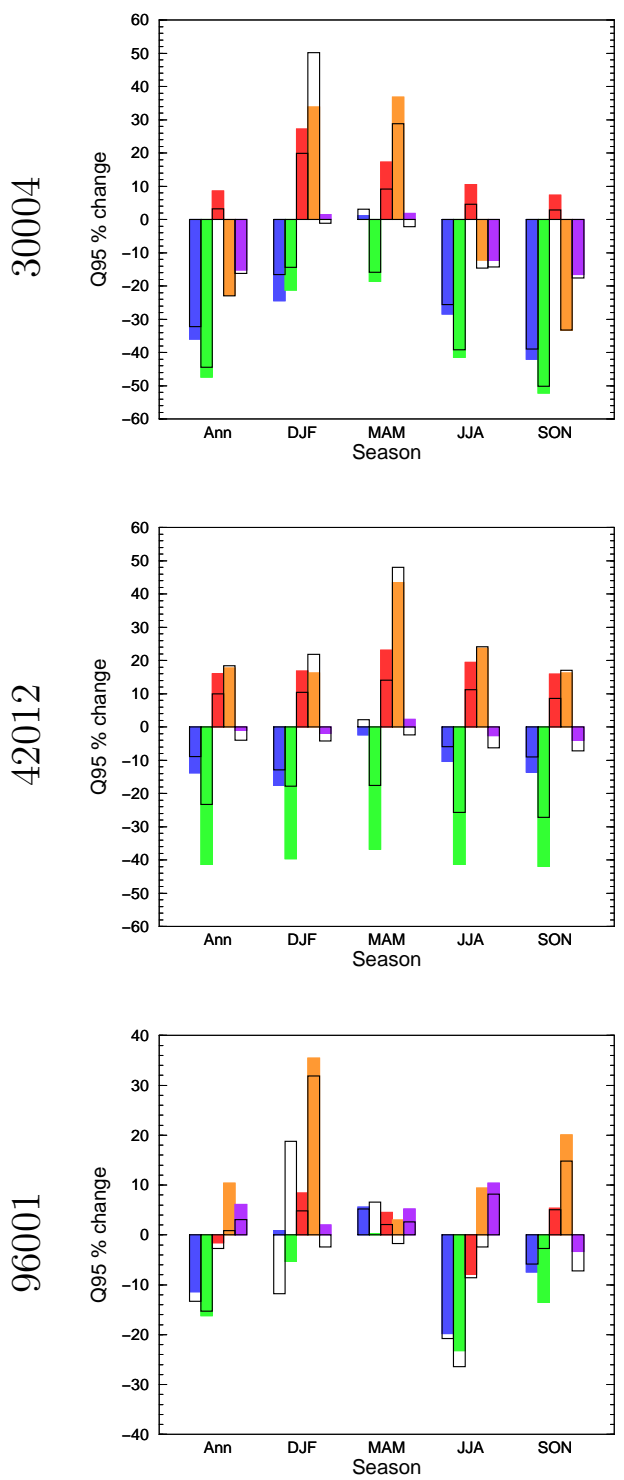

RCMs
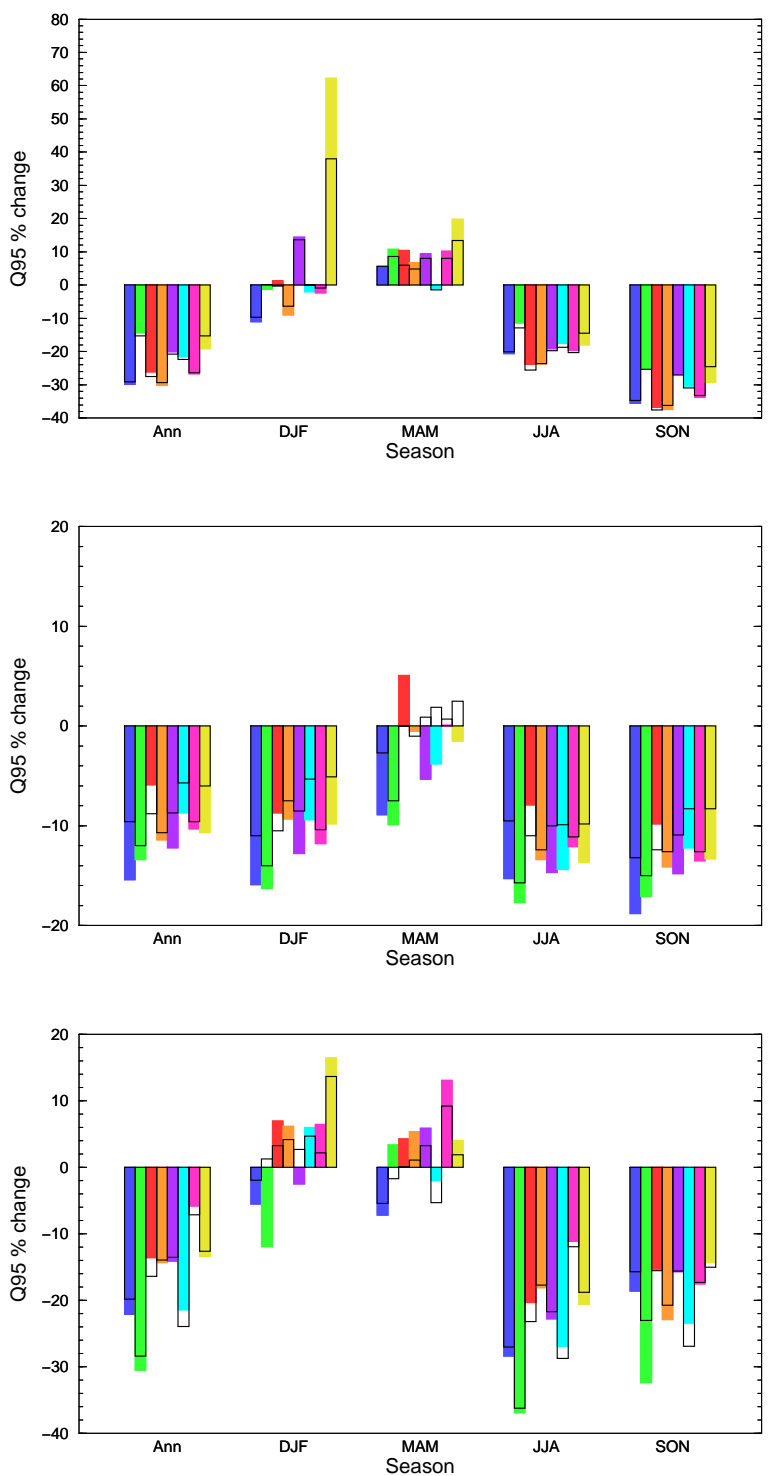

Figure 10 Bar charts showing modelled annual and seasonal percentage changes in Q95 for three example catchments, for each GCM (left-hand column, left-to-right bar order: HadCM3; ECHAM4; CSIRO; CCSR; CGCM2) and RCM (right-hand column, left-to-right bar order: MOHC; DMI; ETH; GKSS; KNMI; MPI; SMHI; UCM). The solid bars indicate the results when the changes in Penman-Monteith PE are applied, whilst the outlined bars indicate the results when the changes in T-based PE are applied instead. 

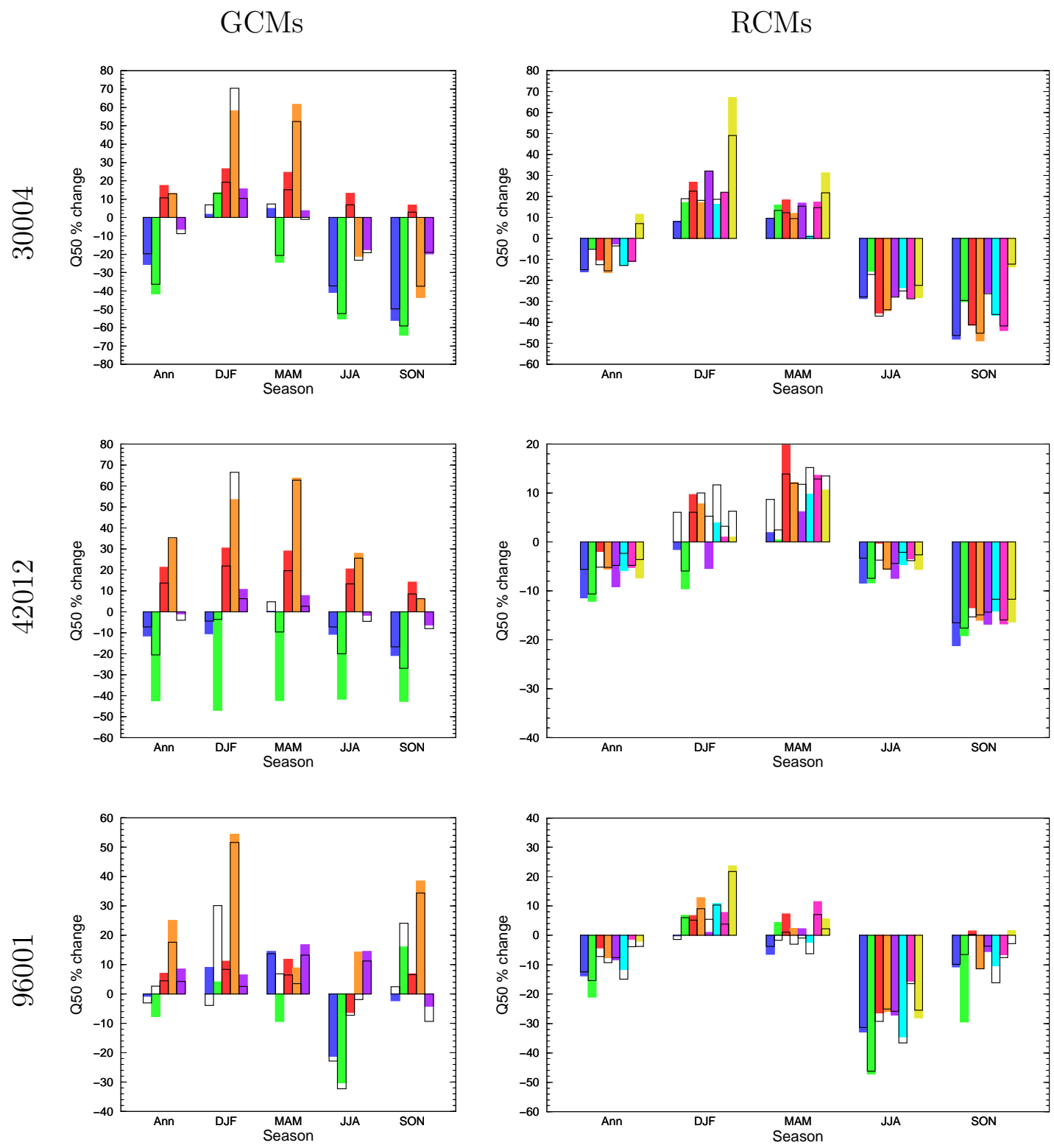

Figure 11 As Figure 10, but showing the modelled annual and seasonal percentage changes in the median flow (Q50). 

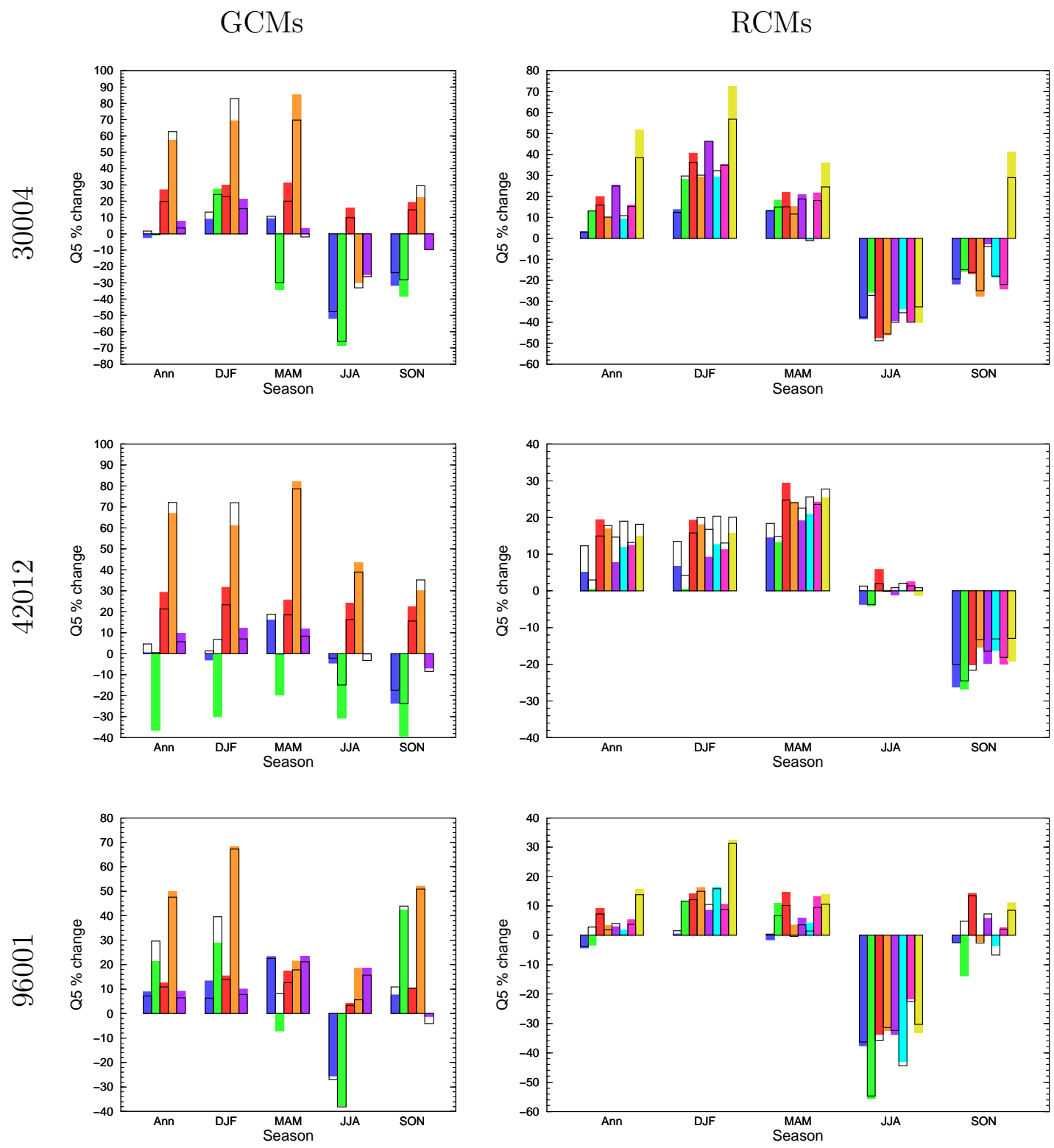

Figure 12 As Figure 10, but showing the modelled annual and seasonal percentage changes in Q5. 
GCMs
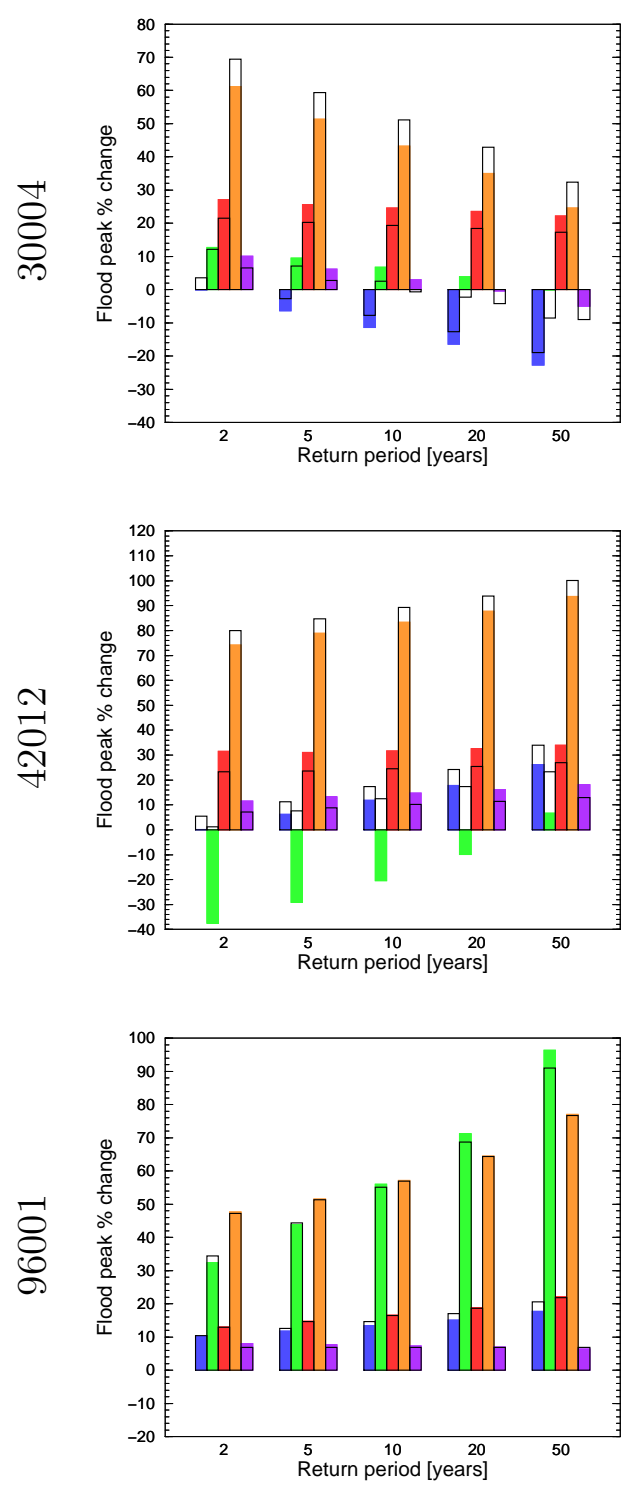

$\mathrm{RCMs}$
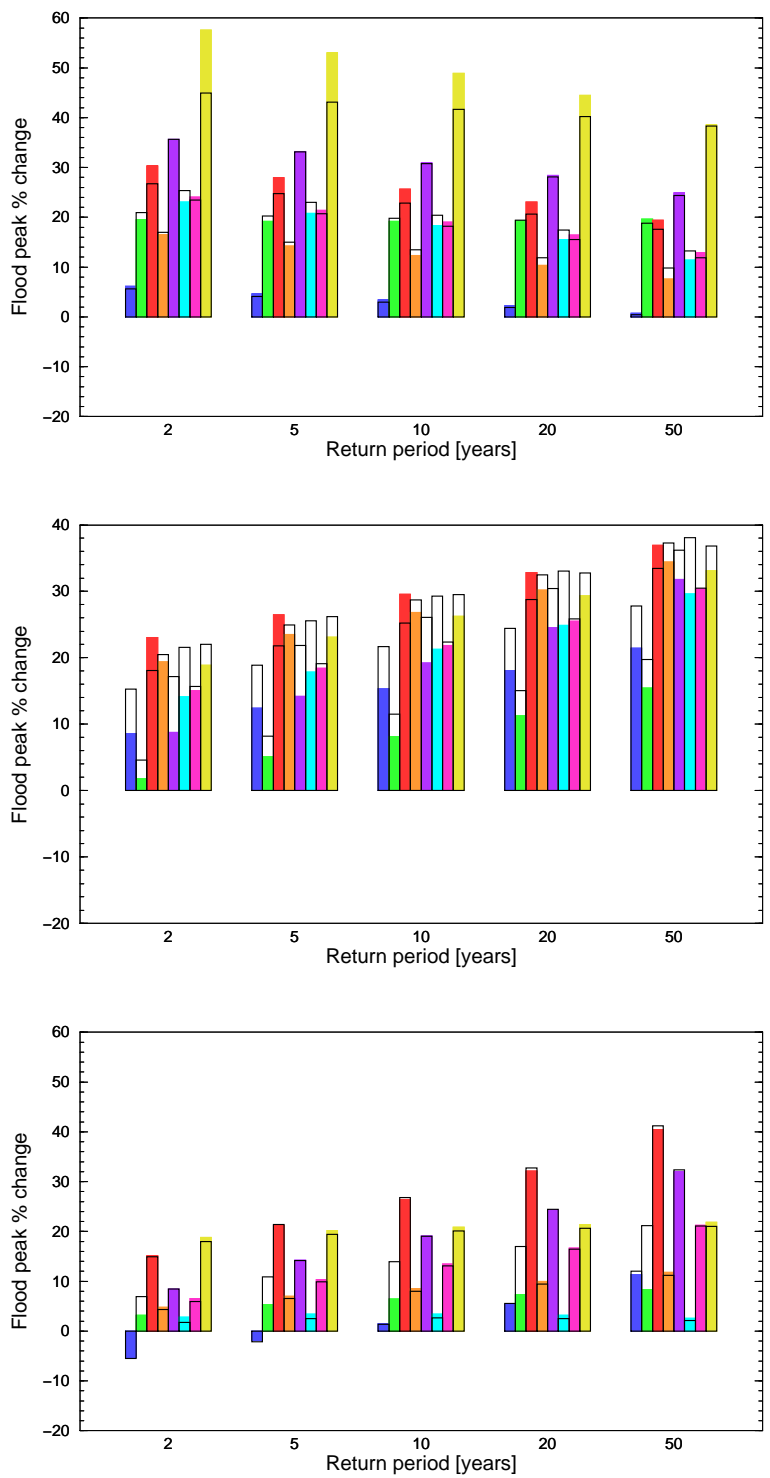

Figure 13 As Figure 10, but showing the modelled percentage changes in flood peaks at five different return periods $(2,5,10,20$ and 50 years $)$. 